\title{
Systematic review of cigar smoking and all cause and smoking related mortality
}

\author{
Cindy M Chang ${ }^{*}$, Catherine G Corey, Brian L Rostron and Benjamin J Apelberg
}

The information in this article is not a formal dissemination of information by the FDA and does not represent agency position or policy. The contents are the responsibility of the authors alone.

\begin{abstract}
Background: Cigars are a growing public health concern, given the changes in cigar use patterns in the US and elsewhere since the 1960s. We conducted a systematic review of published studies on current cigar smoking and all-cause and cause-specific mortality risks to inform potential regulatory approaches and future research that would strengthen the body of evidence.

Methods: Using 3 different databases and handsearching, we identified epidemiological studies published prior to June 2014 that examined the association between cigar smoking and all-cause mortality and smoking-related mortality. Detailed study characteristics as well as association-level characteristics, including effect estimates and 95\% confidence intervals, were abstracted or calculated from each selected study.

Results: A total of 22 studies from 16 different prospective cohorts were identified. Primary cigar smoking (current, exclusive cigar smoking with no history of previous cigarette or pipe smoking) was associated with all cause-mortality, oral cancer, esophageal cancer, pancreatic cancer, laryngeal cancer, lung cancer, coronary heart disease $(\mathrm{CHD})$, and aortic aneurysm. Strong dose trends by cigars per day and inhalation level for primary cigar smoking were observed for oral, esophageal, laryngeal, and lung cancers. Among primary cigar smokers reporting no inhalation, relative mortality risk was still highly elevated for oral, esophageal, and laryngeal cancers.

Conclusions: In summary, cigar smoking carries many of the same health risks as cigarette smoking. Mortality risks from cigar smoking vary by level of exposure as measured by cigars per day and inhalation level and can be as high as or exceed those of cigarette smoking. The body of evidence would be strengthened by future studies that focus on the health effects of primary cigar smoking and incorporate more contemporary and diverse study populations to better reflect the current patterns of cigar use in the US. Ideally, these studies would also collect detailed information on cigar type, exposure level, and biomarkers of exposure and potential harm.
\end{abstract}

Keywords: Cigars, Mortality, Systematic review

\section{Background}

The 2009 Family Smoking Prevention and Tobacco Control Act (FSPTCA) provided the US Food and Drug Administration (FDA) with regulatory authority over the manufacture, distribution, and marketing of cigarettes, rollyour-own tobacco, and smokeless tobacco. In April 2014, the FDA issued a proposed rule to assert jurisdiction over additional tobacco products, including cigars which are a

\footnotetext{
* Correspondence: Cindy.Chang@fda.hhs.gov

Office of Science, Center for Tobacco Products, Food and Drug

Administration, Document Control Center, Building 71, Room G335, 10903 ,

New Hampshire Avenue, Silver Spring, MD 20993-0002, USA
}

growing public health concern [1]. The US Centers for Disease Control and Prevention (CDC) has reported that from 2000 to 2011, cigar consumption more than doubled in the US from slightly less than 6.2 billion sticks in 2000 to more than 13.7 billion in 2011 [2]. Cigarette consumption, on the other hand, declined by $33 \%$ in the US during this period. In the US, the current cigar product landscape varies widely with respect to flavors, pack sizes, brands and cigar types (e.g., large cigars, cigarillos, and little filtered cigars) [3]. Cigar use among youth and young adults has been of particular concern in recent years. Nearly $16 \%$ of US young adults ages 18 to 24 years reported having smoked cigars 
on at least one day in the past 30 days in 2009-2010 [4]. Nationally, $2.8 \%$ of middle school students and $12.6 \%$ of high school students reported having smoked cigars (either cigars, cigarillos or little cigars) on at least one day in the past 30 days [5]. In the same study, cigar smoking prevalence significantly increased from 2011 to 2012 in nonHispanic Black high school students from $11.7 \%$ to $16.7 \%$.

Cigar smoking produces numerous adverse health effects. Cigar smoke contains many of the same toxic constituents as cigarette smoke, and cigar smoke has been shown to have higher levels of tobacco-specific nitrosamines (TSNAs) than cigarette smoke due to the curing and fermentation process for cigar tobacco [6]. Many of these TSNAs such as N-Nitrosonornicotine (NNN) and nicotinederived nitrosamine ketone (NNK) are known carcinogens [6]. Cigar smoke has also been found to have higher levels of carbon monoxide and nitrogen oxide than cigarette smoke [6]. The International Agency of Research on Cancer (IARC) has previously concluded in 2004 that cigar and/or pipe smoking is causally connected to cancers of the lung and upper aerodigestive tract, including the oral cavity, oropharynx, hypopharynx, larynx and esophagus. They also found evidence that cigar and/or pipe smoking are causally associated with cancers of the pancreas, stomach and urinary bladder [7,8]. A recent analysis of the population health effects of cigar smoking found that regular cigar smoking is responsible for at least 9,000 deaths each year in the US and that the total number of deaths may be higher due to potential increases in cigar smoking relative risks over time, perhaps due to more diverse cigar products and changes in inhalation patterns, as well as the possibility of deaths due to other causes that have not been previously linked to cigar smoking [9].

Given the public health and regulatory importance of cigars, it is extremely timely and important to have accurate and comprehensive information on the health effects of these products. This study presents a systematic review of published studies on current cigar smoking and all-cause and cause-specific mortality risks. In doing so, it synthesizes the information currently available on the subject and identifies areas for further research.

\section{Methods}

We conducted a systematic review of epidemiological studies published prior to June 2014 that examined the association between cigar smoking and all-cause and

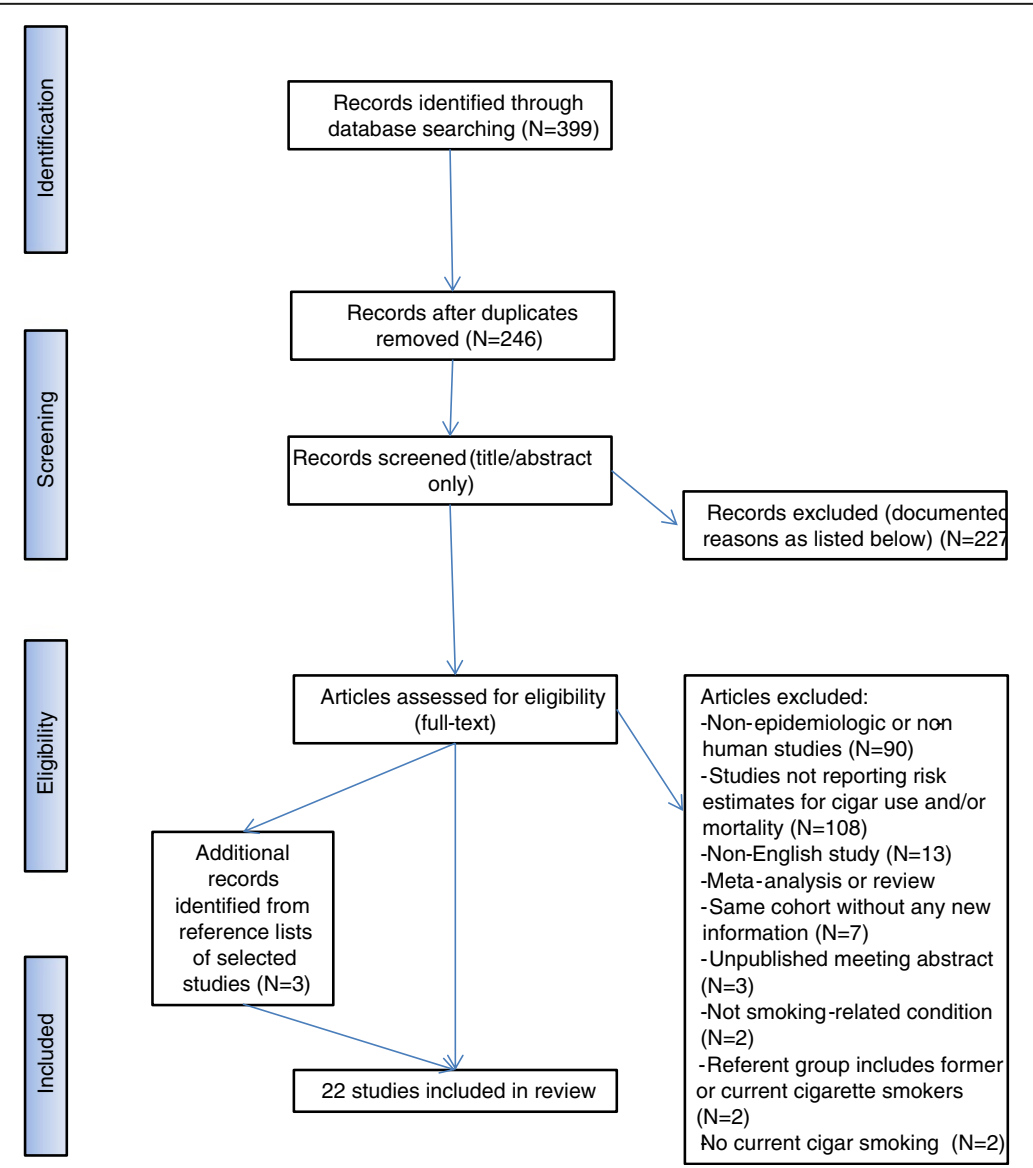

Figure 1 Flowchart of study selection of prospective studies of cigar and all-cause and cause-specific mortality. 
Table 1 Selected prospective studies of cigar smoking and mortality

\begin{tabular}{|c|c|c|c|c|c|c|c|c|c|}
\hline Author & $\begin{array}{l}\text { Publication } \\
\text { year }\end{array}$ & Country & Cohort name & Follow-up & & $\begin{array}{l}\text { Total } \\
\text { participants }\end{array}$ & $\begin{array}{l}\text { Total current cigar } \\
\text { and/pipe smokers }\end{array}$ & Age range & $\begin{array}{l}\text { Effect measure } \\
\text { reported }\end{array}$ \\
\hline Kahn [28] & 1966 & US & Dorn study & 1954-1957 & to 1962 & 248,195 & N/A & 31 to 84 & SMR \\
\hline Best [15] & 1966 & Canada & Canadian Study of Smoking and Health & 1956 & to 1962 & 92,000 & 1,594 & 30 to 90 & SMR \\
\hline Cole [19] & 1974 & Denmark & & 1958 & to 1972 & 183 & N/A & 55 to 64 & Calculated IRR \\
\hline Gordon [36] & 1974 & US & Framingham & 1948-1953 & to $1966-1970$ & 2,336 & 311 & 29 to 62 & Calculated IRR \\
\hline Doll [22] & 1976 & UK & Male British Doctors & 1951 & to 1971 & 34,440 & N/A & 20 and older & Calculated SMR \\
\hline Jajich [27] & 1984 & US & Cook County, IL & 1965 & to 1970 & 2,674 & 265 (18 females) & 65 to 74 & IRR \\
\hline Carstensen [17] & 1987 & Sweden & Swedish Census Cohort & 1963 & to 1979 & 25,129 & N/A & 18 to 69 & SMR \\
\hline Sandler [29] & 1989 & US & Washington, County, MD & 1963 & to 1975 & 46,926 & 1,671 (10 females) & 25 and older & IRR, 95\% Cl \\
\hline Hsing [25] & 1990 & US & Dorn study & 1954-1957 & to 1980 & 249,829 & N/A & 31 to 84 & IRR, 95\% Cl \\
\hline Strachan [34] & 1991 & UK & Nested case-control within Whitehall study cohort & 1967-1969 & to 1987 & 18,403 & N/A & 40 to 64 years & $\mathrm{OR}, 95 \% \mathrm{Cl}$ \\
\hline Lange [30] & 1992 & Denmark & Copenhagen City Heart Study & 1976 & to 1989 & 14,214 & 808 (770 females) & 20 and older & $\mathrm{HR}, 95 \% \mathrm{Cl}$ \\
\hline Chow [21] & 1992 & US & Lutheran Brotherhood Insurance Society & 1966 & to 1986 & 17,818 & N/A & 35 years and older & IRR, 95\% Cl \\
\hline Chow [20] & 1993 & US & Dorn study & 1954-1957 & to 1980 & 248,046 & N/A & 31 to 84 & IRR, 95\% Cl \\
\hline Ben-Shlomo [16] & 1994 & UK & Whitehall study & 1967-1969 & to 1987 & 19,018 & 763 & 40 to 69 & Calculated IRR \\
\hline Heineman [24] & 1995 & US & Dorn study & 1954-1957 & to 1980 & 248,046 & N/A & 31 to 84 & IRR, 95\% Cl \\
\hline Haheim [23] & 1996 & Finland & Oslo study & 1972 & to 1992 & 16,173 & 1,623 & 40 to 49 & $\mathrm{HR}, 95 \% \mathrm{Cl}$ \\
\hline Wald [35] & 1997 & UK & British United Provident Association & 1975-1982 & to 1993 & 21,520 & 1,831 & 35 to 64 & $\mathrm{HR}, 95 \% \mathrm{Cl}$ \\
\hline Shanks [31] & 1998 & US & CPS-I & 1959-1960 & to 1972 & 442,455 & 15,191 (primary) & 30 and older & IRR, 95\% Cl \\
\hline Jacobs [26] & 1999 & US & CPS-II & 1982 & to 1991 & 121,278 & 6,914 & 30 years or older & $\mathrm{HR}, 95 \% \mathrm{Cl}$ \\
\hline Shapiro [33] & 2000 & US & CPS-II & 1982 & to 1994 & 508,353 & 7,888 & 30 years or older & $\mathrm{HR}, 95 \% \mathrm{Cl}$ \\
\hline Chao [18] & 2002 & US & CPS-II & 1982 & to 1996 & 467,788 & 6,945 & 30 years or older & $\mathrm{HR}, 95 \% \mathrm{Cl}$ \\
\hline Shaper [32] & 2003 & UK & British Regional Heart Study & 1978-1989 & to 2000 & 7,121 & 730 & 40 to 59 & $\mathrm{HR}, 95 \% \mathrm{Cl}$ \\
\hline
\end{tabular}


cause-specific mortality. In doing so, we followed guidelines for systematic reviews from the Institute of Medicine (IOM) [10], the Meta-analysis Of Observational Studies in Epidemiology (MOOSE) group [11] and the Cochrane Collaboration [12]. For cause-specific mortality, we selected causes and conditions identified as smoking-related in the 2004 Surgeon General's Report on the health effects of smoking and IARC's 2012 summary monograph "A Review of Human Carcinogens" $[13,14]$. Based on these criteria, studies of cigar smoking and the following causes of death were identified in the research literature and included in this review: oral cancer, nasopharyngeal carcinoma, esophageal cancer, stomach cancer, colon and rectal cancer, liver cancer, pancreatic cancer, laryngeal cancer, lung cancer, bladder cancer, kidney cancer, atherosclerosis, coronary heart disease, stroke, aortic aneurysm, and chronic obstructive pulmonary disease (COPD).

We conducted a search in PubMed using the following terms: (cigar[tw] OR cigars[tw] OR cigarillo[tw] OR cigarillos[tw] OR cheroot[tw] OR cheroots[tw] OR stogies[tw]) AND (death[tw] OR mortality[tw]), yielding 100 potentially

Table 2 Current cigar smoking and all-cause mortality

\begin{tabular}{|c|c|c|c|c|c|c|c|c|}
\hline Study & Cohort name & Sex & $\begin{array}{l}\text { Cigar smoker } \\
\text { deaths }\end{array}$ & $\begin{array}{l}\text { Effect } \\
\text { estimate }\end{array}$ & $95 \% \mathrm{Cl}$ & Measure & $\begin{array}{l}\text { Primary/ } \\
\text { secondary* }\end{array}$ & Adjustment \\
\hline \multicolumn{9}{|l|}{ Current Cigar } \\
\hline Best1966 & $\begin{array}{l}\text { Canadian Study } \\
\text { of Smoking and Health }\end{array}$ & & 196 & 1.06 & $(0.92,1.22)$ & SMR & & Age \\
\hline Kahn1966 & Dorn study & & 1532 & 1.1 & $(1.05,1.16)$ & SMR & & Age \\
\hline Cole1974 & & & 33 & 1.15 & $(0.70,1.90)$ & IRR & & \\
\hline Carstensen 1987 & Swedish Census Cohort & & 131 & 1.39 & $(1.16,1.65)$ & SMR & & Age, residence \\
\hline Lange1992 & $\begin{array}{l}\text { Copenhagen } \\
\text { City Heart Study }\end{array}$ & Men & 326 & 1.6 & $(1.30,2.00)$ & $H R$ & & Age \\
\hline Lange1992 & $\begin{array}{l}\text { Copenhagen } \\
\text { City Heart Study }\end{array}$ & Women & 185 & 1.8 & $(1.40,2.20)$ & $\mathrm{HR}$ & & Age \\
\hline Ben-Shlomo1994 & Whitehall study & & 9 & 0.48 & $(0.25,0.93)$ & $\mathrm{IRR}$ & Primary & Age \\
\hline Ben-Shlomo1994 & Whitehall study & & 132 & 1.2 & $(0.99,1.46)$ & $\mathrm{IRR}$ & Secondary & Age \\
\hline Shanks1998 & CPS-I & & 3754 & 1.08 & $(1.05,1.12)$ & IRR & Primary & Age \\
\hline Shanks1998 & CPS-I & & 1462 & 1.12 & $(1.06,1.18)$ & IRR & Secondary & Age \\
\hline \multicolumn{9}{|c|}{ Current Cigar and/or Pipe } \\
\hline Cole1974 & & & 35 & 1.68 & $(1.03,2.75)$ & IRR & & \\
\hline Gordon 1974 & Framingham & & 52 & 0.76 & $(0.51,1.12)$ & $\mathrm{IRR}$ & & \\
\hline Doll1976 & Male British Doctors & & 388 & 1.09 & $(0.98,1.20)$ & SMR & Primary & Age \\
\hline Doll1976 & Male British Doctors & & 595 & $1.13+$ & $(1.04,1.22)$ & SMR & Secondary & Age \\
\hline Sandler1989 & Washington, County, MD & Men & 504 & 1.2 & $(1.07,1.35)$ & $\mathrm{IRR}$ & & $\begin{array}{l}\text { Age, marital status, } \\
\text { education, quality } \\
\text { of housing }\end{array}$ \\
\hline Sandler1989 & Washington, County, MD & Women & 2 & 0.7 & $(0.18,2.75)$ & IRR & & $\begin{array}{l}\text { Age, marital status, } \\
\text { education, quality } \\
\text { of housing }\end{array}$ \\
\hline Wald1997 & $\begin{array}{l}\text { British United } \\
\text { Provident Association }\end{array}$ & & 113 & 1.23 & $(0.99,1.75)$ & $H R$ & Primary & Age \\
\hline Wald1997 & $\begin{array}{l}\text { British United } \\
\text { Provident Association }\end{array}$ & & 69 & 1.33 & $(1.03,1.73)$ & $H R$ & Secondary & Age \\
\hline Shaper2003 & CPS-II & & 41 & 1.37 & $(0.99,1.91)$ & $H R$ & Primary & $\begin{array}{l}\text { Age, BMI, blood } \\
\text { pressure/hypertension, } \\
\text { serum cholesterol }\end{array}$ \\
\hline Shaper2003 & CPS-II & & 145 & 1.46 & $(1.18,1.79)$ & $\mathrm{HR}$ & Secondary & $\begin{array}{l}\text { Age, BMl, blood } \\
\text { pressure/hypertension, } \\
\text { serum cholesterol }\end{array}$ \\
\hline
\end{tabular}

*Primary cigar smoking: current, exclusive cigar smoking with no previous history of cigarette or pipe smoking; primary cigar and/or pipe smoking: current, exclusive cigar and/or pipe smoking with no previous history of cigarette smoking; secondary cigar smoking: current, exclusive cigar smoking with previous history of cigarette or pipe smoking; secondary cigar and/or pipe smoking: current, exclusive cigar and/or pipe smoking with previous history of cigarette smoking.

tBased on corrected death rate of 1600 per 100,000 [43]. 
Table 3 Current cigar smoking and all-cause mortality by inhalation level and cigars per day

\begin{tabular}{|c|c|c|c|c|c|c|c|}
\hline Study & Cohort name & Inhalation level & Cigars per day & Effect estimate & $95 \% \mathrm{Cl}$ & Measure & Primary/secondary* \\
\hline Kahn1966 & Dorn study & & $<5$ & 1.04 & $(0.98,1.11)$ & SMR & \\
\hline Kahn1966 & Dorn study & & 5 to 8 & 1.17 & $(1.06,1.29)$ & SMR & \\
\hline Kahn1966 & Dorn study & & $8+$ & 1.49 & $(1.24,1.77)$ & SMR & \\
\hline Shanks1998 & CPS-I & & 1 to 2 & 1.02 & $(0.97,1.07)$ & IRR & Primary \\
\hline Shanks1998 & CPS-I & & 3 to 4 & 1.08 & $(1.02,1.15)$ & IRR & Primary \\
\hline Shanks1998 & CPS-I & & $5+$ & 1.17 & $(1.10,1.24)$ & IRR & Primary \\
\hline Shanks1998 & CPS-I & & 1 to 2 & 1.02 & $(0.93,1.12)$ & IRR & Secondary \\
\hline Shanks1998 & CPS-I & & 3 to 4 & 1.17 & $(1.07,1.28)$ & IRR & Secondary \\
\hline Shanks1998 & CPS-I & & $5+$ & 1.18 & $(1.08,1.29)$ & IRR & Secondary \\
\hline Shanks1998 & CPS-I & None & & 1.04 & $(1.00,1.08)$ & IRR & Primary \\
\hline Shanks1998 & CPS-I & Slight & & 1.19 & $(1.09,1.30)$ & IRR & Primary \\
\hline Shanks1998 & CPS-I & Moderate-deep & & 1.6 & $(1.38,1.84)$ & IRR & Primary \\
\hline Shanks1998 & CPS-I & None & & 1.04 & $(0.97,1.11)$ & IRR & Secondary \\
\hline Shanks1998 & CPS-I & Slight & & 1.16 & $(1.04,1.29)$ & IRR & Secondary \\
\hline Shanks1998 & CPS-I & Moderate-deep & & 1.33 & $(1.16,1.51)$ & IRR & Secondary \\
\hline
\end{tabular}

*Primary cigar smoking: current, exclusive cigar smoking with no previous history of cigarette or pipe smoking; secondary cigar smoking: current, exclusive cigar smoking with previous history of cigarette or pipe smoking.

pertinent references. We also conducted a search in EMBASE using the following terms: (cigar OR cigars OR cigarillo OR cigarillos OR cheroot OR cheroots OR stogies) AND ('death'/exp OR death OR 'mortality'/exp OR mortality), yielding 207 potential references. Finally, we searched ISI Web of Science using the terms: Topic $=($ cigar OR cigars OR cigarillo OR cigarillos OR cheroot OR cheroots OR stogies) AND Topic $=($ death OR mortality $)$, yielding 92 potential references. After removing duplicate records among the three search results, there were a total of 246 references.

\section{Study selection}

At each stage of the study screening, two reviewers (CMC and $\mathrm{CGC}$ ) independently reviewed the studies and made selections for inclusion (Figure 1). Final selections were made after discussion and consensus was reached on discrepant results. All selected studies were screened by title and abstract, and the full texts of the subset of relevant papers were then reviewed. A total of 227 references were excluded from review (see Additional file 1).
Because the focus of this review is on studies that examine current cigar smoking at baseline, we excluded an earlier cohort study conducted by the American Cancer Society that looked at mortality risks for lifetime ever cigar smokers (w1-w2). A total of 108 references did not report mortality risk associated with cigar use (w3-w110). An additional 13 non-English studies were also excluded (w111w123). We excluded 90 non-epidemiologic or non-human studies, including reviews and commentaries (w124-w213). Two studies were excluded because they examined causes of death (prostate cancer and multiple myeloma) that were not classified as smoking-related in the 2004 Surgeon General's Report or 2012 IARC monograph (w214-w215). Because the aim of this review was to compare mortality risks relative to never tobacco users or never smokers, two studies with former or current cigarette smokers in their reference groups were excluded (w216-w217). We excluded 7 references because they only contained results from cohort studies that were also published in studies that were selected for review (w218-w224). Three references were

Table 4 Current cigar smoking and oral cancer

\begin{tabular}{|c|c|c|c|c|c|c|c|c|}
\hline Study & Cohort name & $\begin{array}{l}\text { Cigar smoker } \\
\text { deaths }\end{array}$ & $\begin{array}{l}\text { Effect } \\
\text { estimate }\end{array}$ & $95 \% \mathrm{Cl}$ & Measure & $\begin{array}{l}\text { Primary/ } \\
\text { secondary* }\end{array}$ & Adjustment & ICD codes \\
\hline \multicolumn{9}{|l|}{ Current Cigar } \\
\hline Kahn1966 & Dorn study & 9 & 4.11 & $(1.86,7.84)$ & SMR & & Age & ICD 7: 140-150 \\
\hline Shanks1998 & CPS-I & 25 & 7.92 & $(5.12,11.69)$ & IRR & Primary & Age & \\
\hline Shanks1998 & CPS-I & 8 & 6.58 & $(2.83,12.97)$ & IRR & Secondary & Age & \\
\hline Shapiro2000 & CPS-II & 6 & 4 & $(1.50,10.30)$ & $H R$ & Primary & $\begin{array}{l}\text { Age, alcohol, } \\
\text { smokeless tobacco }\end{array}$ & $\begin{array}{l}\text { ICD 9: } 140-141 \text {, } \\
143-149\end{array}$ \\
\hline
\end{tabular}


Table 5 Current cigar smoking and oral cancer by inhalation level, cigars per day, and duration

\begin{tabular}{|c|c|c|c|c|c|c|c|c|}
\hline Study & Cohort name & $\begin{array}{l}\text { Inhalation } \\
\text { level }\end{array}$ & Cigars per day & $\begin{array}{l}\begin{array}{l}\text { Duration } \\
\text { (years) }\end{array} \\
\end{array}$ & Effect estimate & $95 \% \mathrm{Cl}$ & Measure & $\begin{array}{l}\text { Primary/ } \\
\text { secondary* }\end{array}$ \\
\hline Shanks1998 & CPS-I & & 1 to 2 & & 2.12 & $(0.43,6.18)$ & $\mathrm{IRR}$ & Primary \\
\hline Shanks1998 & CPS-I & & 3 to 4 & & 8.51 & $(3.66,16.77)$ & $\mathrm{IRR}$ & Primary \\
\hline Shanks1998 & CPS-I & & $5+$ & & 15.94 & $(8.71,26.75)$ & $\mathrm{IRR}$ & Primary \\
\hline Shanks 1998 & CPS-I & & 1 to 2 & & 4.39 & $(0.06,24.45)$ & $\mathrm{IRR}$ & Secondary \\
\hline Shanks1998 & CPS-I & & $5+$ & & 13.73 & $(5.50,28.30)$ & $\mathrm{IRR}$ & Secondary \\
\hline Shapiro2000 & CPS-II & & 1 to 2 & & 0 & $(0.00,0.00)$ & $\mathrm{HR}$ & Primary \\
\hline Shapiro2000 & CPS-II & & $3+$ & & 7.6 & $(2.90,19.60)$ & $\mathrm{HR}$ & Primary \\
\hline Shanks1998 & CPS-I & None & & & 6.98 & $(4.13,11.03)$ & IRR & Primary \\
\hline Shanks1998 & CPS-I & Slight & & & 7.83 & $(1.57,22.88)$ & $\mathrm{IRR}$ & Primary \\
\hline Shanks1998 & CPS-I & Moderate-d & & & 27.88 & $(5.60,81.46)$ & $\mathrm{IRR}$ & Primary \\
\hline Shanks 1998 & CPS-I & None & & & 3.27 & $(0.66,9.56)$ & $\mathrm{IRR}$ & Secondary \\
\hline Shanks 1998 & CPS-I & Slight & & & 8.75 & $(1.76,25.58)$ & $\mathrm{IRR}$ & Secondary \\
\hline Shanks1998 & CPS-I & Moderate-d & & & 24.19 & $(2.72,87.32)$ & $\mathrm{IRR}$ & Secondary \\
\hline Shapiro2000 & CPS-II & No inhalatio & & & 3.2 & $(0.90,11.00)$ & $\mathrm{HR}$ & Primary \\
\hline Shapiro2000 & CPS-II & Inhalation & & & 6.5 & $(1.40,29.20)$ & $\mathrm{HR}$ & Primary \\
\hline Shapiro2000 & CPS-II & & & $<25$ & 0 & $(0.00,0.00)$ & $\mathrm{HR}$ & Primary \\
\hline Shapiro2000 & CPS-II & & & $25+$ & 4.6 & $(1.60,13.00)$ & $\mathrm{HR}$ & Primary \\
\hline
\end{tabular}

*Primary cigar smoking: current, exclusive cigar smoking with no previous history of cigarette or pipe smoking; secondary cigar smoking: current, exclusive cigar smoking with previous history of cigarette or pipe smoking.

excluded because they were unpublished meeting abstracts (w225-w227). Finally, three additional references were identified by handsearching the references of relevant studies. In total, 22 articles on cigar smoking and all-cause and cause-specific mortality were included in this review [15-36] (Figure 1 and Table 1).

\section{Data extraction}

Two different sets of data were extracted. The first dataset consisted of study-level characteristics including cohort name, country where study was conducted, publication year of study, number of cigar users, age range of cohort participants, year of enrollment, length of follow-up, outcome type (i.e. all-cause or cause-specific mortality), and relative mortality risk measure. The second dataset consisted of association-level characteristics including relative risk estimates as well as characteristics used to stratify estimates such as age, type and level of cigar exposure, and duration of cigar exposure. Thus, multiple entries could occur for a particular study. Additionally, reported International Classification of Diseases (ICD) codes from the relevant revision were extracted for cause-specific mortality estimates. Although one included study, Shanks and Burns (1998), did not report ICD codes in their analysis of Cancer Prevention Study I (CPS-I) data, it can be assumed that their cause of death coding system was similar to ICD 7 , given that similar studies of CPS-I have used ICD 7 codes [37]. Data extraction was independently conducted by two reviewers (CMC and CGC). Similar to the selection of studies, data entries were compared and any differences in data extraction were resolved through discussion.

Table 6 Current cigar smoking and esophageal cancer

\begin{tabular}{|c|c|c|c|c|c|c|c|c|}
\hline Study & Cohort name & $\begin{array}{l}\text { Cigar smoker } \\
\text { deaths }\end{array}$ & $\begin{array}{l}\text { Effect } \\
\text { estimate }\end{array}$ & $95 \% \mathrm{Cl}$ & Measure & $\begin{array}{l}\text { Primary/ } \\
\text { secondary* }\end{array}$ & Adjustment & ICD codes \\
\hline \multicolumn{9}{|l|}{ Current Cigar } \\
\hline Kahn1966 & Dorn study & 12 & 5.33 & $(2.74,9.34)$ & SMR & & Age & ICD 8: 150 \\
\hline Carstensen 1987 & Swedish Census Cohort & 2 & 6.5 & $(0.61,23.90)$ & SMR & & Age, residence & ICD 8: 150 \\
\hline Shanks1998 & CPS-I & 19 & 3.6 & $(2.17,5.62)$ & IRR & Primary & Age & \\
\hline Shanks1998 & CPS-I & 7 & 3.52 & $(1.41,7.25)$ & $\mathrm{IRR}$ & Secondary & Age & \\
\hline Shapiro2000 & CPS-\| & 9 & 1.8 & $(0.90,3.70)$ & $\mathrm{HR}$ & Primary & $\begin{array}{l}\text { Age, alcohol, } \\
\text { smokeless tobacco }\end{array}$ & ICD 9: 150 \\
\hline
\end{tabular}


Table 7 Current cigar smoking and esophageal cancer by inhalation level, cigars per day, and duration

\begin{tabular}{|c|c|c|c|c|c|c|c|c|}
\hline Study & Cohort name & Inhalation level & Cigars per day & $\begin{array}{l}\text { Duration } \\
\text { (years) }\end{array}$ & $\begin{array}{l}\text { Effect } \\
\text { estimate }\end{array}$ & $95 \% \mathrm{Cl}$ & Measure & $\begin{array}{l}\text { Primary/ } \\
\text { secondary* }\end{array}$ \\
\hline Shanks1998 & CPS-I & & 1 to 2 & & 2.28 & $(0.74,5.33)$ & IRR & Primary \\
\hline Shanks1998 & CPS-I & & 3 to 4 & & 3.93 & $(1.43,8.55)$ & IRR & Primary \\
\hline Shanks 1998 & CPS-I & & $5+$ & & 5.19 & $(2.23,10.22)$ & IRR & Primary \\
\hline Shanks1998 & CPS-I & & 1 to 2 & & 2.64 & $(0.03,14.67)$ & IRR & Secondary \\
\hline Shanks 1998 & CPS-I & & 3 to 4 & & 1.56 & $(0.02,8.68)$ & IRR & Secondary \\
\hline Shanks1998 & CPS-I & & $5+$ & & 5.63 & $(1.81,13.14)$ & IRR & Secondary \\
\hline Shapiro2000 & CPS-\| & & 1 to 2 & & 1.8 & $(0.60,5.00)$ & $\mathrm{HR}$ & Primary \\
\hline Shapiro2000 & CPS-\| & & $3+$ & & 1.9 & $(0.80,4.90)$ & $\mathrm{HR}$ & Primary \\
\hline Shanks 1998 & CPS-I & None & & & 3.4 & $(1.90,5.61)$ & IRR & Primary \\
\hline Shanks1998 & CPS-I & Slight & & & 1.9 & $(0.02,10.58)$ & IRR & Primary \\
\hline Shanks1998 & CPS-I & Moderate-deep & & & 14.84 & $(2.98,43.37)$ & IRR & Primary \\
\hline Shanks1998 & CPS-I & None & & & 4.15 & $(1.34,9.68)$ & IRR & Secondary \\
\hline Shanks1998 & CPS-I & Slight & & & 2.22 & $(0.03,12.37)$ & IRR & Secondary \\
\hline Shanks 1998 & CPS-I & Moderate-deep & & & 2.69 & $(0.04,14.94)$ & IRR & Secondary \\
\hline Shapiro2000 & CPS-II & No inhalation & & & 1.6 & $(0.70,4.10)$ & $H R$ & Primary \\
\hline Shapiro2000 & CPS-II & Inhalation & & & 1 & $(0.10,7.20)$ & $\mathrm{HR}$ & Primary \\
\hline Shapiro2000 & CPS-II & & & $<25$ & 0.9 & $(0.10,6.40)$ & $\mathrm{HR}$ & Primary \\
\hline Shapiro2000 & CPS-II & & & $25+$ & 2.2 & $(1.00,4.70)$ & $H R$ & Primary \\
\hline
\end{tabular}

*Primary cigar smoking: current, exclusive cigar smoking with no previous history of cigarette or pipe smoking; secondary cigar smoking: current, exclusive cigar smoking with previous history of cigarette or pipe smoking.

A number of studies did not report 95\% confidence intervals and/or relative mortality risks (see "Effect measure reported" column in Table 1). For these studies, we calculated these estimates using the available data. For standardized mortality ratios (SMRs), we used the relevant formula from Breslow et al. (equation 2.15) to calculate 95\% confidence intervals [38]. For incidence rate ratios (IRRs), we calculated 95\% confidence intervals using Wald Limits [39].

The main exposure of interest was either current exclusive cigar smoking or current exclusive cigar/pipe smoking. Current cigarette smokers are excluded from this analysis to better isolate the effects of cigar smoking on disease risk. Past cigarette smoking patterns are likely to affect current cigar smoking patterns. CPS-I results suggest that secondary cigar smokers (current, exclusive cigar smoking with a history of previous cigarette or pipe smoking) are about twice as likely to report inhaling cigar smoke as primary cigar smokers (current, exclusive cigar smoking with no history of previous cigarette or pipe smoking) (42.0\% vs. 21.6\%) [31]. Therefore, secondary cigar smokers may have different disease risks compared with primary cigar smokers not only due to past cigarette use, but also due to differences in cigar use, particularly with inhalation. Thus, for studies that assessed this information, we present results for primary and secondary cigar smokers separately as well as separate studies that combine cigar and pipe use from studies of cigar use only.

\section{Results}

In total, there were 22 selected studies that examined cigar smoking and mortality from 16 cohorts (Table 1 ). All of the studies were from prospective cohorts for which vital status was usually determined through either active follow-up or linkage to a death registry (Strachan conducted a case-control study nested within a prospective cohort [34]). Four studies were published from

Table 8 Current cigar smoking and stomach cancer

\begin{tabular}{lllllll}
\hline Study & $\begin{array}{l}\text { Cohort } \\
\text { name }\end{array}$ & $\begin{array}{l}\text { Cigar smoker } \\
\text { deaths }\end{array}$ & $\begin{array}{l}\text { Effect } \\
\text { estimate }\end{array}$ & $\mathbf{9 5 \%} \mathbf{C l}$ & Measure & Adjustment \\
\hline $\begin{array}{llll}\text { Current Cigar } \\
\text { Kahn1966 }\end{array}$ & Dorn Study & 23 & 1.2 & $(0.76,1.80)$ & SMR & Age \\
Chao2002 & CPS-II & 25 & 2.29 & $(1.49,3.51)$ & HR & $\begin{array}{l}\text { Age, education, race, family history of stomach } \\
\text { cancer,high-fiber grain foods, vegetables, citrus } \\
\text { fruits/juices, }\end{array}$ \\
\hline
\end{tabular}


Table 9 Current cigar smoking and stomach cancer by inhalation level, cigars per day, duration, and age started smoking cigars

\begin{tabular}{|c|c|c|c|c|c|c|c|c|c|}
\hline Study & Cohort name & $\begin{array}{l}\text { Inhalation } \\
\text { level }\end{array}$ & $\begin{array}{l}\text { Cigars } \\
\text { per day }\end{array}$ & Duration (years) & $\begin{array}{l}\text { Age started } \\
\text { cigars (years) }\end{array}$ & Effect estimate & $95 \% \mathrm{Cl}$ & P-trend & Measure \\
\hline Chao2002 & CPS-II & & 1 to 4 & & & 1.68 & $(0.95,2.97)$ & & $\mathrm{HR}$ \\
\hline Chao2002 & CPS-II & & $5+$ & & & 4.2 & $(2.32,7.60)$ & 0.746 & $\mathrm{HR}$ \\
\hline Chao2002 & CPS-II & None & & & & 2.08 & $(1.22,3.57)$ & & $\mathrm{HR}$ \\
\hline Chao2002 & CPS-II & Slight to deep & & & & 3.93 & $(1.92,8.04)$ & & $\mathrm{HR}$ \\
\hline Chao2002 & CPS-II & & & $\leq 39$ & & 2.42 & $(1.36,4.28)$ & & $H R$ \\
\hline Chao2002 & CPS-II & & & $\geq 40$ & & 2.55 & $(1.32,4.94)$ & 0.079 & $\mathrm{HR}$ \\
\hline Chao2002 & CPS-II & & & & $\leq 19$ & 2.78 & 1.236 .28 & & $\mathrm{HR}$ \\
\hline Chao2002 & CPS-II & & & & $20-29$ & 3.01 & 1.655 .49 & & $H R$ \\
\hline Chao2002 & CPS-II & & & & $\geq 30$ & 1.74 & 0.714 .24 & 0.617 & $H R$ \\
\hline
\end{tabular}

the Dorn study cohort which approximately 250,000 government life-insurance policy holders (mostly US World War I veterans) responded to questionnaires on tobacco use mailed to them in the 1950s. Two studies were published from the Whitehall study cohort in which over 18,000 men aged 40-69 years from the British Civil Service underwent an examination between 1967 and 1969 which included reporting health history and lifetime smoking habits. Finally, three studies were published from the American Cancer Society's Cancer Prevention Study II (CPS-II) cohort in which over a half million male volunteers from all 50 US states completed a self-administered questionnaire in 1982. Women were not included in CPS-II studies of cigar use because they were not asked if they smoked cigars. One of the 16 cohorts began in the 1940s, five cohorts began in the 1950s, five cohorts began in the 1960s, four cohorts began in the 1970s, and one cohort began in the 1980s. The studies were conducted primarily in North America and Europe with 12 in the US, five in the United Kingdom (UK), one in Canada, and four in Nordic countries (Denmark, Sweden, and Finland).

We found a substantial amount of variation across studies in terms of study characteristics including the definition of tobacco exposure (e.g. assessment of past cigarette smoking, inclusion of current pipe smoking), dose categories, and adjustment for possible confounding risk factors. Furthermore, CPS-I and II were the only cohorts large enough to yield results for primary cigar smokers and secondary cigar smokers separately for most outcomes. Thus, we present the results descriptively, rather than giving pooled relative risk estimates.
In the subsequent results, we refer to effect estimates as "mortality ratios" or MRs, regardless of whether they are age-standardized mortality ratios, hazards ratios (HR), incidence rate ratios (IRR) or odds ratios (OR). We present MRs for current cigar smoking only (rather than ever or former cigar smoking). The referent group is never smokers or never tobacco users. Results for allcause mortality and cause-specific mortality are presented. Estimates for groups of causes, such as cancers of the digestive system or genitourinary system, were not included in our results. For each outcome, we present results in the following order of exposure: primary cigar smoking (current, exclusive cigar smoking with no previous history of cigarette or pipe smoking), primary cigar and/or pipe smoking (current, exclusive cigar and/or pipe smoking with no previous history of cigarette smoking), secondary cigar smoking (current, exclusive cigar smoking with previous history of cigarette or pipe smoking), secondary cigar and/or pipe smoking (current, exclusive cigar and/or pipe smoking with previous history of cigarette smoking), any current cigar smoking (regardless of cigarette/pipe smoking history), and any current cigar/pipe smoking (regardless of cigarette smoking history). Following overall cigar exposure, we then present results (when available) by level of cigar exposure (cigars per day), inhalation (any or the reported level), and duration of cigar smoking.

\section{All-cause mortality}

All-cause mortality results are presented in Tables 2 and 3. Two studies reported all-cause mortality risk among primary cigar smokers. Shanks and Burns found a

Table 10 Current cigar smoking and liver cancer

\begin{tabular}{llllllll}
\hline Study & Cohort name & Cigar smoker deaths & Effect estimate & $\mathbf{9 5 \%}$ CI & Measure & Adjustment & ICD codes \\
\hline Carstensen1987 & Swedish Census Cohort & 4 & 7.2 & $(1.87,18.62)$ & SMR & Age, residence & ICD 8: 155-156 \\
Hsing1990 & Dorn study & 47 & 3.1 & $(2.00,4.80)$ & IRR & Age, calendar time & ICD 7: 155.0 \\
\hline
\end{tabular}


Table 11 Current cigar smoking and pancreatic cancer

\begin{tabular}{|c|c|c|c|c|c|c|c|c|}
\hline Study & Cohort name & $\begin{array}{l}\text { Cigar smoker } \\
\text { deaths }\end{array}$ & $\begin{array}{l}\text { Effect } \\
\text { estimate }\end{array}$ & $95 \% \mathrm{Cl}$ & Measure & $\begin{array}{l}\text { Primary/ } \\
\text { secondary* }\end{array}$ & Adjustment & ICD codes \\
\hline \multicolumn{9}{|l|}{ Current Cigar } \\
\hline Kahn1966 & Dorn study & 27 & 1.52 & $(1.00,2.21)$ & SMR & & Age & ICD 7: 157 \\
\hline Carstensen 1987 & Swedish Census Cohort & 1 & 1 & $(0.00,5.73)$ & SMR & & Age, residence & $\begin{array}{l}\text { ICD 8: 140-146, } \\
148,161\end{array}$ \\
\hline Shanks1998 & CPS-I & 56 & 1.62 & $(1.22,2.11)$ & $\mathrm{IRR}$ & Primary & Age & \\
\hline Shanks1998 & CPS-I & 20 & 1.8 & $(1.10,2.78)$ & $\mathrm{IRR}$ & Secondary & Age & \\
\hline Shapiro2000 & CPS-II & 28 & 1.3 & $(0.90,1.90)$ & $\mathrm{HR}$ & Primary & $\begin{array}{l}\text { Age, alcohol, } \\
\text { smokeless tobacco }\end{array}$ & ICD 9: 157 \\
\hline
\end{tabular}

*Primary cigar smoking: current, exclusive cigar smoking with no previous history of cigarette or pipe smoking; secondary cigar smoking: current, exclusive cigar smoking with previous history of cigarette or pipe smoking.

significant positive association $(\mathrm{MR}=1.08,95 \% \mathrm{CI}=$ 1.05-1.12) based on 3,754 cigar smoker deaths in CPS-I, whereas Ben-Shlomo reported an inverse association between cigar smoking and all-cause mortality based on a much smaller cohort with only 9 cigar smoker deaths (Table 2). In three cigar studies that also included pipe smoking, primary pipe/cigar smoking was associated with slight increases in all-cause mortality risks (MRs 1.09 to 1.37), and all of these associations just missed conventional thresholds for statistical significance with the lower bounds of the $95 \%$ confidence intervals being at least 0.98. All-cause mortality risks were increased in two studies reporting risks for secondary cigar smoking
(MRs 1.12 to 1.20 ), and one association was statistically significant while the other just missed statistical significance with 0.99 as the lower bound of the $95 \%$ confidence interval. All three studies on secondary cigar/pipe smoking found significant increases in all-cause mortality (MRs 1.13 to 1.46). Overall, MRs for all-cause mortality among current cigar smokers ranged from 0.48 to 1.60 and 0.70 to 1.68 among current cigar/pipe smokers. Among primary cigar smokers in CPS-1, smoking 3 or more cigars per day (MRs 1.08-1.17) and higher levels of cigar smoke inhalation (MRs 1.19-1.60) were both associated with significantly increased risk of all-cause mortality (Table 3).

Table 12 Current cigar smoking and pancreatic cancer by inhalation level, cigars per day, and duration

\begin{tabular}{|c|c|c|c|c|c|c|c|c|}
\hline Study & $\begin{array}{l}\text { Cohort } \\
\text { name }\end{array}$ & $\begin{array}{l}\text { Inhalation } \\
\text { level }\end{array}$ & $\begin{array}{l}\text { Cigars } \\
\text { per day }\end{array}$ & $\begin{array}{l}\text { Duration } \\
\text { (years) }\end{array}$ & $\begin{array}{l}\text { Effect } \\
\text { estimate }\end{array}$ & $95 \% \mathrm{Cl}$ & Measure & $\begin{array}{l}\text { Primary/ } \\
\text { secondary* }\end{array}$ \\
\hline Shanks1998 & CPS-I & & 1 to 2 & & 1.18 & $(0.69,1.89)$ & IRR & Primary \\
\hline Shanks 1998 & CPS-I & & 3 to 4 & & 1.51 & $(0.86,2.45)$ & IRR & Primary \\
\hline Shanks1998 & CPS-1 & & $5+$ & & 2.21 & $(1.40,3.32)$ & IRR & Primary \\
\hline Shanks1998 & CPS-I & & 1 to 2 & & 0.56 & $(0.06,2.01)$ & IRR & Secondary \\
\hline Shanks1998 & CPS-1 & & 3 to 4 & & 1.9 & $(0.82,3.74)$ & IRR & Secondary \\
\hline Shanks1998 & CPS-I & & $5+$ & & 3.71 & $(1.78,6.83)$ & IRR & Secondary \\
\hline Shapiro2000 & CPS-II & & 1 to 2 & & 0.6 & $(0.30,1.40)$ & $\mathrm{HR}$ & Primary \\
\hline Shapiro2000 & CPS-II & & $3+$ & & 1.6 & $(1.00,2.50)$ & $H R$ & Primary \\
\hline Shanks1998 & CPS-I & None & & & 1.55 & $(1.12,2.07)$ & IRR & Primary \\
\hline Shanks1998 & CPS-I & Slight & & & 2.16 & $(0.99,4.10)$ & IRR & Primary \\
\hline Shanks 1998 & CPS-I & Moderate-deep & & & 2.26 & $(0.45,6.60)$ & IRR & Primary \\
\hline Shanks1998 & CPS-I & None & & & 1.55 & $(0.80,2.72)$ & IRR & Secondary \\
\hline Shanks1998 & CPS-I & Slight & & & 1.92 & $(0.52,4.92)$ & IRR & Secondary \\
\hline Shanks1998 & CPS-I & Moderate-deep & & & 2.53 & $(0.51,7.39)$ & IRR & Secondary \\
\hline Shapiro2000 & CPS-II & No inhalation & & & 0.9 & $(0.50,1.50)$ & $H R$ & Primary \\
\hline Shapiro2000 & CPS-II & Inhalation & & & 2.7 & $(1.50,4.80)$ & $\mathrm{HR}$ & Primary \\
\hline Shapiro2000 & CPS-II & & & $<25$ & 1.5 & $(0.70,3.30)$ & $H R$ & Primary \\
\hline Shapiro2000 & CPS-II & & & $25+$ & 1.1 & $(0.70,1.80)$ & $\mathrm{HR}$ & Primary \\
\hline
\end{tabular}


Table 13 Current cigar smoking and laryngeal cancer

\begin{tabular}{lllllllll}
\hline Study & Cohort name & $\begin{array}{l}\text { Cigar smoker } \\
\text { deaths }\end{array}$ & Effect estimate & $\mathbf{9 5 \% ~ C l}$ & Measure & $\begin{array}{l}\text { Primary/ } \\
\text { secondary* }\end{array}$ & Adjustment & ICD codes \\
\hline $\begin{array}{l}\text { Current Cigar } \\
\text { Kahn1966 }\end{array}$ & Dorn study & 6 & 10.33 & $(3.72,22.63)$ & SMR & & Age & ICD 7: 161 \\
Shanks1998 & CPS-I & 7 & 10.02 & $(4.01,20.64)$ & IRR & Primary & Age & Age, alcohol, \\
Shapiro2000 & CPS-II & 4 & 10.3 & $(2.60,41.00)$ & HR & Primary & ICD 9: 161 \\
& & & & & & & smokeless tobacco & \\
\hline
\end{tabular}

*Primary cigar smoking: current, exclusive cigar smoking with no previous history of cigarette or pipe smoking; secondary cigar smoking: current, exclusive cigar smoking with previous history of cigarette or pipe smoking.

\section{Oral cancer}

Results for mortality from oral cancer are presented in Tables 4 and 5. Shanks and Burns and Shapiro, Jacobs, and Thun both found significantlyelevated risk of oral cancer mortality for primary cigar smokers in CPS-I and II (Table 4). Secondary cigar smoking was also significantly associated with death from oral cancer in CPS-I. Overall, current cigar smoking MRs ranged from 4 to 7.9. Strong dose-response trends were observed for cigars per day, level of inhalation, and duration in both studies of primary cigar smoking in CPS-I and II (Table 5). Primary cigar smokers reporting no inhalation also had significantly elevated risk of oral cancer mortality in CPS-I $(\mathrm{MR}=6.98,95 \% \mathrm{CI}=4.13-11.03)$. Risk of oral cancer was elevated but not statistically significant $(\mathrm{MR}=2.12$, 95\% CI $=0.43-6.18)$ among primary cigar smokers who smoked 1-2 cigars per day in CPS-I, presumably due to small sample size, based on the wide confidence interval. Risk could not be estimated in CPSII due to 0 exposed cases smoking 1-2 cigars per day.

\section{Esophageal cancer}

Results for deaths from esophageal cancer are presented in Tables 6 and 7. Shanks and Burns observed a significant positive association between primary cigar smoking and esophageal cancer mortality in CPS-I $(\mathrm{MR}=3.60$,
95\% CI $=2.17-5.62$ ) based on 19 exposed cases (Table 6). Shapiro, Jacobs, and Thun observed an elevated, but non-significant association in CPS-II $(M R=1.80,95 \%$ $\mathrm{CI}=0.90-3.70)$ based on 9 exposed cases, and was thus underpowered to detect this association. Shanks and Burns also observed a significant association for secondary cigar smoking in CPS-I. Current cigar smoking MRs ranged from 1.8 to 6.5. In CPS-I, Shanks and Burns found strong dose-response trends for cigars per day and depth of inhalation among primary cigar smokers (Table 7), even though an elevated risk was still observed among those reporting no inhalation $(\mathrm{MR}=3.40,95 \%$ $\mathrm{CI}=1.90,5.61)$. Risk of esophageal cancer was elevated but not statistically significant among primary cigar smokers who smoked 1-2 cigars per day in both CPS-I $(\mathrm{MR}=2.28,95 \% \mathrm{CI}=0.74-5.33)$ and CPS-II $(\mathrm{MR}=1.80$, $95 \% \mathrm{CI}=0.60-5.00$, based on 4 exposed cases). Based on the wide confidence intervals, both cohorts appear to be underpowered to detect an association at this level of exposure due to small sample size.

\section{Stomach cancer}

Mortality risk estimates for stomach cancer are presented in Tables 8 and 9. Overall, current cigar smoking MRs were 1.2 in the Dorn study cohort and 2.29 from CPS-II, with the estimate from CPS-II being statistically

Table 14 Current cigar smoking and laryngeal cancer by inhalation level, cigars per day, and duration

\begin{tabular}{llllllll}
\hline Study & Cohort name & Inhalation level & Cigars per day & $\begin{array}{l}\text { Duration } \\
\text { (years) }\end{array}$ & Effect estimate & $\mathbf{9 5 \%}$ Cl & $\begin{array}{l}\text { Measure } \\
\text { Primary/ } \\
\text { secondary* }\end{array}$ \\
\hline Shanks1998 & CPS-I & 1 to 2 & & 6.45 & $(0.72,23.27)$ & IRR & Primary \\
Shanks1998 & CPS-I & $5+$ & 26.03 & $(8.39,60.74)$ & IRR & Primary \\
Shapiro2000 & CPS-II & & 1 to 2 & 6 & $(0.70,53.50)$ & HR & Primary \\
Shapiro2000 & CPS-II & $3+$ & 15 & $(3.40,65.90)$ & HR & Primary \\
Shanks1998 & CPS-I & None & & 10.6 & $(3.87,23.07)$ & IRR & Primary \\
Shanks1998 & CPS-I & Moderate-deep & & 53.26 & $(0.70,296.32)$ & IRR & Primary \\
Shapiro2000 & CPS-II & No inhalation & & 4.2 & $(0.50,37.10)$ & HR & Primary \\
Shapiro2000 & CPS-II & Inhalation & & 39 & $(8.40,180.10)$ & HR & Primary \\
Shapiro2000 & CPS-II & & $<25$ & 0 & $(0.00,0.00)$ & HR & Primary \\
Shapiro2000 & CPS-II & & $25+$ & 13.7 & $(3.40,54.50)$ & HR & Primary \\
\hline
\end{tabular}

*Primary cigar smoking: current, exclusive cigar smoking with no previous history of cigarette or pipe smoking; secondary cigar smoking: current, exclusive cigar smoking with previous history of cigarette or pipe smoking. 
Table 15 Current cigar smoking and lung cancer

\begin{tabular}{|c|c|c|c|c|c|c|c|c|c|}
\hline Study & Cohort name & Sex & $\begin{array}{l}\text { Cigar } \\
\text { smoker } \\
\text { deaths }\end{array}$ & $\begin{array}{l}\text { Effect } \\
\text { estimate }\end{array}$ & $95 \% \mathrm{Cl}$ & Measure & $\begin{array}{l}\text { Primary/ } \\
\text { secondary* }\end{array}$ & Adjustment & $\begin{array}{l}\text { ICD } \\
\text { codes }\end{array}$ \\
\hline \multicolumn{10}{|l|}{ Current Cigar } \\
\hline Kahn1966 & Dorn study & & 25 & 1.59 & $(1.03,2.35)$ & SMR & & Age & ICD 7: 162-163 \\
\hline Carstensen 1987 & $\begin{array}{l}\text { Swedish Census } \\
\text { Cohort }\end{array}$ & & 11 & 7.6 & $(3.77,13.65)$ & SMR & & Age, residence & ICD 8: 162 \\
\hline Lange1992 & $\begin{array}{l}\text { Copenhagen City } \\
\text { Heart Study }\end{array}$ & Men & 47 & 6 & $(2.20,17.00)$ & $H R$ & & Age & ICD 8: 162 \\
\hline Lange1992 & $\begin{array}{l}\text { Copenhagen City } \\
\text { Heart Study }\end{array}$ & Women & 14 & 4.9 & $(3.00,12.00)$ & $\mathrm{HR}$ & & Age & ICD 8: 162 \\
\hline Ben-Shlomo1994 & Whitehall study & & 1 & 1.8 & $(0.24,13.31)$ & IRR & Primary & Age & ICD 8: 162 \\
\hline Ben-Shlomo1994 & Whitehall study & & 20 & 7.64 & $(4.22,13.83)$ & IRR & Secondary & Age & ICD 8: 162 \\
\hline Shanks1998 & CPS-I & & 73 & 2.1 & $(1.63,2.65)$ & IRR & Primary & Age & \\
\hline Shanks1998 & CPS-I & & 83 & 6.29 & $(5.01,7.79)$ & IRR & Secondary & Age & \\
\hline Shapiro2000 & CPS-II & & 88 & 5.1 & $(4.00,6.60)$ & $H R$ & Primary & $\begin{array}{l}\text { Age, alcohol, } \\
\text { smokeless } \\
\text { tobacco }\end{array}$ & ICD 9: 162 \\
\hline \multicolumn{10}{|c|}{ Current Cigar and/or Pipe } \\
\hline Chow1992 & Dorn study & & 4 & 3.5 & $(1.00,12.60)$ & $H R$ & & Age, occupation & \\
\hline Wald1997 & $\begin{array}{l}\text { British United } \\
\text { Provident Association }\end{array}$ & & 6 & 3.19 & $(1.07,9.50)$ & $\mathrm{HR}$ & Primary & Age & ICD 9: 162 \\
\hline Wald1997 & $\begin{array}{l}\text { British United } \\
\text { Provident Association }\end{array}$ & & 9 & 8.64 & $(3.19,23.30)$ & $\mathrm{HR}$ & Secondary & Age & ICD 9: 162 \\
\hline
\end{tabular}

*Primary cigar smoking: current, exclusive cigar smoking with no previous history of cigarette or pipe smoking; primary cigar and/or pipe smoking: current, exclusive cigar and/or pipe smoking with no previous history of cigarette smoking; secondary cigar smoking: current, exclusive cigar smoking with previous history of cigarette or pipe smoking; secondary cigar and/or pipe smoking: current, exclusive cigar and/or pipe smoking with previous history of cigarette smoking.

significant (Table 8). Stronger associations were observed for the highest levels of both cigars per day and inhalation in CPS-II (Table 9). Cigar smoking was found to be associated with stomach cancer mortality in CPSII for both less than 40 years of cigar smoking and 40 years or more of cigar smoking.

\section{Liver cancer}

Results for liver cancer are presented in Table 10. Studies of liver cancer mortality risk for cigar smoking are limited. Both studies of current cigar smoking showed significant associations with deaths from liver cancer; however, neither study reported cigarette smoking history.

\section{Pancreatic cancer}

Results for deaths from pancreatic cancer are presented in Tables 11 and 12. Shanks and Burns found a significant association between primary cigar smoking and pancreatic cancer mortality in CPS-I, while Shapiro, Jacobs, and Thun did not find a significant association in CPS-II (Table 11). Shanks and Burns also found a significant association with pancreatic cancer mortality risk for secondary cigar smokers. Overall, current cigar smoking MRs ranged from 1 to 1.8. A weak dose-response trend was seen for cigars per day in CPS-I and II (Table 12). Inhalation was associated with pancreatic cancer mortality in CPS-II, and some evidence of a dose-response trend for inhalation was observed in CPS-I.

\section{Laryngeal cancer}

The results for deaths from laryngeal cancer are presented in Tables 13 and 14. Shanks and Burns and Shapiro, Jacobs, and Thun found significant positive associations between primary cigar smoking and laryngeal cancer mortality risk in CPS-I and CPS-II that were of similar magnitude $($ MRs $=10)$ (Table 13). Kahn also found a significant association of the same magnitude among current cigar smokers. Shanks and Burns and Shapiro, Jacobs, and Thun observed a strong dose-response relationship for cigars per day and level of inhalation, and Shapiro, Jacobs, and Thun observed similar trends for duration of cigar smoking (Table 14). Shanks and Burns also observed that primary cigar smokers reporting no inhalation in CPS-I had significantly elevated risk of mortality from laryngeal cancer $(\mathrm{MR}=10.6,95 \% \mathrm{CI}=3.87-23.07)$. Risk of laryngeal cancer was highly elevated but not statistically significant among primary cigar smokers who smoked 1-2 cigars per day in both CPS-I $(\mathrm{MR}=6.45,95 \% \mathrm{CI}=0.72-23.27)$ and CPS-II (MR $=6.00,95 \%$ CI-0.70-53.50, based on 1 exposed case). Based on the wide confidence intervals, both 
Table 16 Current cigar smoking and lung cancer by inhalation level, cigars per day, and duration

\begin{tabular}{|c|c|c|c|c|c|c|c|c|}
\hline Study & Cohort name & $\begin{array}{l}\text { Inhalation } \\
\text { level }\end{array}$ & $\begin{array}{l}\text { Cigars } \\
\text { per day }\end{array}$ & $\begin{array}{l}\begin{array}{l}\text { Duration } \\
\text { (years) }\end{array} \\
\end{array}$ & Effect estimate & $95 \% \mathrm{Cl}$ & Measure & $\begin{array}{l}\text { Primary/ } \\
\text { secondary* }\end{array}$ \\
\hline Kahn1966 & Dorn study & & $<5$ & & 1.14 & $(0.59,2.00)$ & SMR & \\
\hline Kahn1966 & Dorn study & & 5 to 8 & & 2.64 & $(1.31,4.74)$ & SMR & \\
\hline Kahn1966 & Dorn study & & $8+$ & & 2.07 & $(0.20,7.61)$ & SMR & \\
\hline Shanks 1998 & CPS-I & & 1 to 2 & & 0.9 & $(0.54,1.66)$ & IRR & Primary \\
\hline Shanks1998 & CPS-I & & 3 to 4 & & 2.36 & $(1.49,3.54)$ & IRR & Primary \\
\hline Shanks1998 & CPS-I & & $5+$ & & 3.4 & $(2.34,4.77)$ & IRR & Primary \\
\hline Shanks1998 & CPS-I & & 1 to 2 & & 3.18 & $(1.78,5.24)$ & IRR & Secondary \\
\hline Shanks1998 & CPS-I & & 3 to 4 & & 8.52 & $(5.87,11.97)$ & IRR & Secondary \\
\hline Shanks1998 & CPS-I & & $5+$ & & 7.21 & $(5.02,10.03)$ & IRR & Secondary \\
\hline Shapiro2000 & CPS-II & & 1 to 2 & & 1.3 & $(0.70,2.40)$ & $H R$ & Primary \\
\hline Shapiro2000 & CPS-II & & $3+$ & & 7.8 & $(5.90,10.30)$ & $H R$ & Primary \\
\hline Shanks 1998 & CPS-I & None & & & 1.97 & $(1.48,2.57)$ & IRR & Primary \\
\hline Shanks 1998 & CPS-I & Slight & & & 1.89 & $(0.81,3.72)$ & IRR & Primary \\
\hline Shanks1998 & CPS-I & Moderate-deep & & & 4.93 & $(1.80,10.72)$ & IRR & Primary \\
\hline Shanks1998 & CPS-I & None & & & 5.41 & $(3.93,7.27)$ & IRR & Secondary \\
\hline Shanks1998 & CPS-I & Slight & & & 7.63 & $(4.66,11.78)$ & IRR & Secondary \\
\hline Shanks 1998 & CPS-I & Moderate-deep & & & 9.77 & $(5.88,15.25)$ & IRR & Secondary \\
\hline Shapiro2000 & CPS-II & No inhalation & & & 3.3 & $(2.30,4.70)$ & $H R$ & Primary \\
\hline Shapiro2000 & CPS-II & Inhalation & & & 11.3 & $(7.90,16.10)$ & $\mathrm{HR}$ & Primary \\
\hline Shapiro2000 & CPS-II & & & $<25$ & 2.1 & $(1.00,4.20)$ & $H R$ & Primary \\
\hline Shapiro2000 & CPS-II & & & $25+$ & 5.9 & $(4.50,7.70)$ & $\mathrm{HR}$ & Primary \\
\hline
\end{tabular}

*Primary cigar smoking: current, exclusive cigar smoking with no previous history of cigarette or pipe smoking; secondary cigar smoking: current, exclusive cigar smoking with previous history of cigarette or pipe smoking.

cohorts appear to be underpowered to detect an association at this level of exposure due to small sample size.

\section{Lung cancer}

Lung cancer mortality risk estimates are presented in Tables 15 and 16. Shanks and Burns and Shapiro, Jacobs, and Thun found significant positive associations with lung cancer mortality risk in CPS-I and II, although Ben-Shlomo did not observe a significant association in a much smaller cohort (Table 15). Wald found a significant association between primary cigar/pipe smoking and lung cancer mortality risk. Shanks and Burns and Ben-Shlomo found a significant positive association between lung cancer mortality and secondary cigar smoking as did Wald for secondary cigar/pipe smoking. Overall, current cigar smoking MRs ranged from 1.59 to 7.64, and current cigar/pipe smoking MRs ranged from 3.19 to 8.64. Dose-response trends were observed for cigars per day, level of inhalation, and duration in CPS-I and II data (Table 16).

Table 17 Current cigar smoking and bladder cancer

\begin{tabular}{|c|c|c|c|c|c|c|c|c|}
\hline Study & Cohort name & $\begin{array}{l}\text { Cigar smoker } \\
\text { deaths }\end{array}$ & $\begin{array}{l}\text { Effect } \\
\text { estimate }\end{array}$ & $95 \% \mathrm{Cl}$ & Measure & $\begin{array}{l}\text { Primary/ } \\
\text { secondary* }\end{array}$ & Adjustment & ICD codes \\
\hline \multicolumn{9}{|l|}{ Current Cigar } \\
\hline Kahn1966 & Dorn study & 10 & 0.94 & $(0.45,1.74)$ & SMR & & Age & ICD 7: 181 \\
\hline Carstensen 1987 & Swedish Census Cohort & 1 & 1.9 & $(0.00,10.89)$ & SMR & & Age, residence & ICD 8: 188 \\
\hline Shanks1998 & CPS-I & 25 & 1.38 & $(0.89,2.04)$ & IRR & Primary & Age & \\
\hline Shanks1998 & CPS-I & 9 & 1.23 & $(0.56,2.33)$ & $\mathrm{IRR}$ & Secondary & Age & \\
\hline Shapiro2000 & CPS-II & 6 & 1 & $(0.40,2.30)$ & $\mathrm{HR}$ & Primary & $\begin{array}{l}\text { Age, alcohol, } \\
\text { smokeless tobacco }\end{array}$ & ICD 9: 188 \\
\hline
\end{tabular}


Table 18 Current cigar smoking and bladder cancer by inhalation level, cigars per day, and duration

\begin{tabular}{|c|c|c|c|c|c|c|c|c|}
\hline Study & Cohort name & Inhalation level & $\begin{array}{l}\text { Cigars } \\
\text { per day }\end{array}$ & $\begin{array}{l}\begin{array}{l}\text { Duration } \\
\text { (years) }\end{array} \\
\end{array}$ & Effect estimate & $95 \% \mathrm{Cl}$ & Measure & $\begin{array}{l}\text { Primary/ } \\
\text { secondary* }\end{array}$ \\
\hline Shanks1998 & CPS-I & & 1 to 2 & & 0.78 & $(0.29,1.71)$ & IRR & Primary \\
\hline Shanks1998 & CPS-I & & 3 to 4 & & 1.68 & $(0.77,3.18)$ & IRR & Primary \\
\hline Shanks 1998 & CPS-I & & $5+$ & & 2.03 & $(0.97,3.73)$ & IRR & Primary \\
\hline Shanks 1998 & CPS-I & & 1 to 2 & & 1.02 & $(0.20,2.97)$ & $\mathrm{IRR}$ & Secondary \\
\hline Shanks1998 & CPS-I & & 3 to 4 & & 2.36 & $(0.76,5.50)$ & $\mathrm{IRR}$ & Secondary \\
\hline Shanks 1998 & CPS-I & & $5+$ & & 0.32 & $(0.00,1.80)$ & IRR & Secondary \\
\hline Shapiro2000 & CPS-II & & 1 to 2 & & 0 & $(0.00,0.00)$ & $\mathrm{HR}$ & Primary \\
\hline Shapiro2000 & CPS-II & & $3+$ & & 1.9 & $(0.80,4.40)$ & $H R$ & Primary \\
\hline Shanks1998 & CPS-I & None & & & 1.57 & $(1.00,2.36)$ & IRR & Primary \\
\hline Shanks1998 & CPS-I & Moderate-deep & & & 1.52 & $(0.02,8.44)$ & IRR & Primary \\
\hline Shanks1998 & CPS-I & None & & & 0.77 & $(0.21,1.98)$ & IRR & Secondary \\
\hline Shanks 1998 & CPS-I & Slight & & & 2.87 & $(0.58,8.40)$ & IRR & Secondary \\
\hline Shanks 1998 & CPS-I & Moderate-deep & & & 1.45 & $(0.16,5.25)$ & IRR & Secondary \\
\hline Shapiro2000 & CPS-II & No inhalation & & & 0.5 & $(0.10,2.10)$ & $\mathrm{HR}$ & Primary \\
\hline Shapiro2000 & CPS-\| & Inhalation & & & 3.6 & $(1.30,9.90)$ & $\mathrm{HR}$ & Primary \\
\hline Shapiro2000 & CPS-II & & & $<25$ & 0 & $(0.00,0.00)$ & $\mathrm{HR}$ & Primary \\
\hline Shapiro2000 & CPS-II & & & $25+$ & 1.1 & $(0.40,2.70)$ & $\mathrm{HR}$ & Primary \\
\hline
\end{tabular}

*Primary cigar smoking: current, exclusive cigar smoking with no previous history of cigarette or pipe smoking; secondary cigar smoking: current, exclusive cigar smoking with previous history of cigarette or pipe smoking.

\section{Bladder cancer}

The results for deaths from bladder cancer are presented in Tables 17 and 18. Neither Shanks and Burns nor Shapiro, Jacob, and Thun found an association between primary cigar smoking and bladder cancer mortality risk in CPS-I and CPS-II, respectively, and Shanks and Burns did not find an association with secondary cigar smoking (Table 17). Overall, current cigar smoking MRs ranged from 0.94 to 1.9 . There was no dose-response trend for cigars per day among primary and secondary cigar smokers in both CPS-I and CPS-II. Shanks and Burns did not find increased mortality risk with depth of inhalation in CPS-I, but Shapiro, Jacobs, and Thun did find a significant association with inhalation among primary cigar smokers (Table 18).

\section{Coronary heart disease}

Mortality results due to coronary heart disease (CHD) are presented in Tables 19 and 20. Primary cigar smoking was significantly associated with CHD mortality in CPS-I $(M R=1.05,95 \% \quad C I=1.00-1.11)$. Primary cigar smoking was also associated with CHD mortality in CPS-II men aged 30-74 years $(\mathrm{MR}=1.30,95 \% \mathrm{CI}=$ 1.05-1.62), but not in men 75 years and older. Primary cigar smoking was also not associated with CHD mortality in the much smaller Whitehall study cohort. The one study on primary cigar/pipe smoking from Wald did not observe an increased risk of death from CHD. CPS-I also found increased CHD mortality risk to be associated with secondary cigar smoking $(\mathrm{MR}=1.09,95 \% \mathrm{CI}=$ 1.01-1.18), although the small Whitehall study cohort did not. Wald did not find an association between secondary cigar/pipe smoking and CHD mortality risk. Overall, the current cigar smoking MRs ranged from 0.45 to 1.30 , and the current cigar/pipe MRs ranged from 0.98 to 1.67. There was a weak dose-response relationship with cigars per day and level of inhalation among primary but not secondary cigar smokers in the CPS-I study (Table 20). Primary cigar smoking for 25 years or more was also associated with increased CHD mortality risk in CPS-II men aged 30-74 years.

\section{Stroke}

Results for stroke are presented in Tables 21 and 22. Shanks and Burns did not find a significant association with stroke mortality risk for either primary or secondary cigar smoking in CPS-I (Table 21). Overall, current cigar smoking MRs ranged from 0.92 to 1.08 , and Haheim found a significantly increased risk of death from stroke for cigar/pipe smoking $(\mathrm{MR}=3.6,95 \% \mathrm{CI}=$ 1.05-12.3). However, there was no dose-response trend for cigars per day and level of inhalation among primary and secondary cigar smokers in CPS-I (Table 22).

\section{Aortic aneurysm}

Mortality risk estimates for aortic aneurysm are presented in Tables 23 and 24. Shanks and Burns found significant positive associations for aortic aneurysm 
Table 19 Current cigar smoking and coronary heart disease

\begin{tabular}{|c|c|c|c|c|c|c|c|c|}
\hline Study & Cohort name & $\begin{array}{l}\text { Cigar } \\
\text { smoker } \\
\text { deaths }\end{array}$ & $\begin{array}{l}\text { Effect } \\
\text { estimate }\end{array}$ & $95 \% \mathrm{Cl}$ & Measure & $\begin{array}{l}\text { Primary/ } \\
\text { secondary* }\end{array}$ & Adjustment & ICD codes \\
\hline \multicolumn{9}{|l|}{ Current Cigar } \\
\hline Kahn1966 & Dorn study & 623 & 1.04 & $(0.96,1.13)$ & SMR & & Age & ICD 7: 420 \\
\hline Carstensen 1987 & Swedish Census Cohort & 42 & 1.16 & $(0.84,1.57)$ & SMR & & Age, residence & ICD 8: 410-414 \\
\hline Ben-Shlomo1994 & Whitehall study & 4 & 0.45 & $(0.17,1.22)$ & $\mathrm{IRR}$ & Primary & Age & ICD 8: 410-414 \\
\hline Ben-Shlomo1994 & Whitehall study & 42 & 0.91 & $(0.65,1.27)$ & IRR & Secondary & Age & ICD 8: 410-414 \\
\hline Shanks 1998 & CPS-I & 1505 & 1.05 & $(1.00,1.11)$ & IRR & Primary & Age & \\
\hline Shanks1998 & CPS-I & 609 & 1.09 & $(1.01,1.18)$ & $\mathrm{IRR}$ & Secondary & Age & \\
\hline Jacobs1999 & CPS-II (age 30-74 years) & 98 & 1.30 & $(1.05,1.62)$ & $H R$ & Primary & $\begin{array}{l}\text { Age, BMl, blood pressure/ } \\
\text { hypertension, alcohol } \\
\text { consumption, education, } \\
\text { exercise level, environmental } \\
\text { tob smoke, vit C supplements }\end{array}$ & ICD 9: 410-414 \\
\hline Jacobs1999 & CPS-II (age 75+ years) & 64 & 0.93 & $(0.72,1.21)$ & $\mathrm{HR}$ & Primary & $\begin{array}{l}\text { Age, BMl, blood pressure/ } \\
\text { hypertension, alcohol } \\
\text { consumption, education, } \\
\text { exercise level, environmental } \\
\text { tob smoke, vit C supplements }\end{array}$ & ICD 9: 410-414 \\
\hline \multicolumn{9}{|c|}{ Current Cigar and/or Pipe } \\
\hline Jajich1984 & Cook County, IL & 32 & 1.67 & $(1.11,2.50)$ & IRR & & & \\
\hline Wald1997 & $\begin{array}{l}\text { British United } \\
\text { Provident Association }\end{array}$ & 33 & 0.98 & $(0.67,1.44)$ & $H R$ & Primary & Age & ICD 9: 410-414 \\
\hline Wald1997 & $\begin{array}{l}\text { British United } \\
\text { Provident Association }\end{array}$ & 25 & 1.29 & $(0.88,1.99)$ & $H R$ & Secondary & Age & ICD 9: 410-414 \\
\hline
\end{tabular}

*Primary cigar smoking: current, exclusive cigar smoking with no previous history of cigarette or pipe smoking; primary cigar and/or pipe smoking: current, exclusive cigar and/or pipe smoking with no previous history of cigarette smoking; secondary cigar smoking: current, exclusive cigar smoking with previous history of cigarette or pipe smoking; secondary cigar and/or pipe smoking: current, exclusive cigar and/or pipe smoking with previous history of cigarette smoking.

mortality for both primary and secondary cigar smoking in CPS-I (Table 23). Overall, current cigar smoking MRs ranged from 1.76 to 5.10, while Strachan found that current cigar/pipe smoking was associated with a five-fold increased risk of death from aortic aneurysm $(\mathrm{MR}=5.40,95 \% \mathrm{CI}=1.90-15.30)$. There were no clear dose-response trends for cigars per day and levels of inhalation with in CPS-I (Table 24). Notably, risk of aortic aneurysm was significantly elevated among primary cigar smokers who smoked 1-2 cigars per day in CPS-I $(\mathrm{MR}=1.82,95 \% \mathrm{CI}=1.11-2.81)$.

\section{COPD}

Results for deaths from chronic obstructive pulmonary disease (COPD) are presented in Tables 25 and 26. Shanks and Burns found that COPD mortality was not associated with primary cigar smoking but was significantly associated with secondary cigar smoking $(\mathrm{MR}=$ 4.39, 95\% CI $=3.02-6.16$ ) in CPS-I (Table 25). Wald found that COPD mortality was not associated with primary cigar/pipe smoking but was significantly associated with secondary cigar/pipe smoking. Overall, current cigar smoking MRs ranged from 0.79 to 4.39, while current cigar/pipe smoking MRs ranged from 1.11 to 1.68. For cigars per day, there were no dose-response trends for primary cigar smoking, but there were strong dose-response trends for secondary cigar smoking in CPS-I (Table 26). For level of inhalation, there were suggestive dose-response trends for primary and secondary cigar smoking.

\section{Other causes of death}

For a number of causes of death (atherosclerosis, cancers of the kidney, nasopharynx, colon and rectum), there were only single estimates of associations with cigar smoking (Table 27). All estimates come from the Dorn study cohort. Although estimates for colon and rectal cancer were also reported by Kahn, Heineman reported more up-to-date associations for these cancer sites. Only colon and rectal cancer were significantly associated with primary current cigar/pipe smoking after adjusting for age, calendar time, year of questionnaire response, SES, sedentary job. For colon cancer only, there was a significant dose-trend for the number of cigars smoked a day after adjusting for the same factors ( $p$-trend $=0.004$, data not shown). 
Table 20 Current cigar smoking and coronary heart disease by inhalation level, cigars per day and duration

\begin{tabular}{|c|c|c|c|c|c|c|c|c|}
\hline Study & Cohort name & Inhalation level & $\begin{array}{l}\text { Cigars } \\
\text { per day }\end{array}$ & $\begin{array}{l}\begin{array}{l}\text { Duration } \\
\text { (years) }\end{array} \\
\end{array}$ & $\begin{array}{l}\text { Effect } \\
\text { estimate }\end{array}$ & $95 \% \mathrm{Cl}$ & Measure & $\begin{array}{l}\text { Primary/ } \\
\text { secondary* }\end{array}$ \\
\hline Kahn1966 & Dorn study & & $<5$ & & 1 & $(0.90,1.10)$ & SMR & \\
\hline Kahn1966 & Dorn study & & 5 to 8 & & 1.1 & $(0.94,1.28)$ & SMR & \\
\hline Kahn1966 & Dorn study & & $8+$ & & 1.18 & $(0.86,1.59)$ & SMR & \\
\hline Shanks1998 & CPS-I & & 1 to 2 & & 0.98 & $(0.91,1.07)$ & IRR & Primary \\
\hline Shanks1998 & CPS-I & & 3 to 4 & & 1.06 & $(0.96,1.16)$ & $\mathrm{IRR}$ & Primary \\
\hline Shanks1998 & CPS-I & & $5+$ & & 1.14 & $(1.03,1.24)$ & IRR & Primary \\
\hline Shanks1998 & CPS-I & & 1 to 2 & & 1.06 & $(0.92,1.21)$ & $\mathrm{IRR}$ & Secondary \\
\hline Shanks1998 & CPS-I & & 3 to 4 & & 1.1 & $(0.95,1.27)$ & IRR & Secondary \\
\hline Shanks1998 & CPS-I & & $5+$ & & 1.1 & $(0.96,1.26)$ & IRR & Secondary \\
\hline Jacobs1999 & CPS-II (age 30-74 years) & & 1 & & 1.18 & $(0.76,1.82)$ & $\mathrm{HR}$ & Primary \\
\hline Jacobs 1999 & CPS-II (age 30-74 years) & & 2 to 3 & & 1.43 & $(1.03,1.99)$ & $H R$ & Primary \\
\hline Jacobs 1999 & CPS-II (age 30-74 years) & & $4+$ & & 1.33 & $(0.95,1.86)$ & $\mathrm{HR}$ & Primary \\
\hline Jacobs1999 & CPS-II (age 75+ years) & & 1 & & 1.07 & $(0.64,1.78)$ & $H R$ & Primary \\
\hline Jacobs1999 & CPS-II (age $75+$ years) & & 2 to 3 & & 0.72 & $(0.45,1.16)$ & $\mathrm{HR}$ & Primary \\
\hline Jacobs 1999 & CPS-II (age 75+ years) & & $4+$ & & 1.03 & $(0.70,1.51)$ & $\mathrm{HR}$ & Primary \\
\hline Shanks1998 & CPS-I & None & & & 1.01 & $(0.96,1.07)$ & IRR & Primary \\
\hline Shanks1998 & CPS-I & Slight & & & 1.23 & $(1.07,1.41)$ & IRR & Primary \\
\hline Shanks1998 & CPS-I & Moderate-deep & & & 1.37 & $(1.07,1.75)$ & IRR & Primary \\
\hline Shanks1998 & CPS-I & None & & & 1.02 & $(0.92,1.13)$ & $\mathrm{IRR}$ & Secondary \\
\hline Shanks1998 & CPS-I & Slight & & & 1.1 & $(0.93,1.30)$ & $\mathrm{IRR}$ & Secondary \\
\hline Shanks1998 & CPS-I & Moderate-deep & & & 1.23 & $(0.99,1.51)$ & IRR & Secondary \\
\hline Jacobs1999 & CPS-II (age 30-74 years) & No inhalation & & & 1.25 & $(0.96,1.62)$ & $H R$ & Primary \\
\hline Jacobs1999 & CPS-II (age 30-74 years) & Inhalation & & & 1.6 & $(1.06,2.41)$ & $\mathrm{HR}$ & Primary \\
\hline Jacobs1999 & CPS-II (age 75+ years) & No inhalation & & & 0.87 & $(0.62,1.22)$ & $\mathrm{HR}$ & Primary \\
\hline Jacobs1999 & CPS-II (age 75+ years) & Inhalation & & & 0.93 & $(0.49,1.75)$ & $\mathrm{HR}$ & Primary \\
\hline Jacobs 1999 & CPS-II (age 30-74 years) & & & $<25$ & 1.03 & $(0.64,1.65)$ & $H R$ & Primary \\
\hline Jacobs1999 & CPS-II (age 30-74 years) & & & $25+$ & 1.42 & $(1.11,1.82)$ & $\mathrm{HR}$ & Primary \\
\hline Jacobs1999 & CPS-II (age 75+ years) & & & $<25$ & 0.75 & $(0.28,2.00)$ & $\mathrm{HR}$ & Primary \\
\hline Jacobs1999 & CPS-II (age 75+ years) & & & $25+$ & 0.95 & $(0.70,1.28)$ & $H R$ & Primary \\
\hline
\end{tabular}

*Primary cigar smoking: current, exclusive cigar smoking with no previous history of cigarette or pipe smoking; secondary cigar smoking: current, exclusive cigar smoking with previous history of cigarette or pipe smoking.

\section{Discussion}

We have conducted a systematic review of the mortality risks associated with cigar smoking that identified 22 studies from 16 cohorts that assessed the relative mortality risks of cigar smokers compared with never tobacco users or never smokers. There was substantial variation across studies in terms of study characteristics including exposure definitions, types of effect measures, and adjustments for confounding. We prioritized estimates of primary cigar smoking (vs. never tobacco users or never smokers) with the aim of isolating the health effects of cigar smoking apart from other current or past tobacco smoking. We also placed emphasis on the larger cohorts, primarily the American Cancer Society's Cancer
Prevention Study I (CPS-I) and to a lesser extent CPS-II, which was conducted more recently than CPS-I but had half the number of primary cigar smokers as CPS-I (7,888 and 15,191 primary cigar smokers, respectively). The following mortality outcomes were significantly associated with primary cigar smoking overall in one or both CPS cohorts: all cause-mortality; oral cancer, esophageal cancer, pancreatic cancer, laryngeal cancer, lung cancer, coronary heart disease (CHD), and aortic aneurysm. Dose trends (cigars per day) for primary cigar smoking were observed for oral, esophageal, laryngeal, and lung cancers. Increased risks for oral, esophageal, laryngeal, and lung cancers were observed with increasing or any inhalation. It is notable that relative mortality risk 
Table 21 Current cigar smoking and stroke

\begin{tabular}{|c|c|c|c|c|c|c|c|c|}
\hline Study & Cohort name & $\begin{array}{l}\text { Cigar smoker } \\
\text { deaths }\end{array}$ & $\begin{array}{l}\text { Effect } \\
\text { estimate }\end{array}$ & $95 \% \mathrm{Cl}$ & Measure & $\begin{array}{l}\text { Primary/ } \\
\text { secondary* }\end{array}$ & Adjustment & ICD codes \\
\hline \multicolumn{9}{|l|}{ Current Cigar } \\
\hline Kahn1966 & Dorn study & 135 & 1.08 & $(0.91,1.28)$ & SMR & & Age & ICD 7: 330-334 \\
\hline Shanks1998 & CPS-I & 431 & 0.96 & $(0.87,1.06)$ & IRR & Primary & Age & \\
\hline Shanks1998 & CPS-I & 133 & 0.92 & $(0.77,1.09)$ & $\mathrm{IRR}$ & Secondary & Age & \\
\hline \multicolumn{9}{|c|}{ Current Cigar and/or Pipe } \\
\hline Haheim 1996 & Oslo study & 7 & 3.6 & $(1.05,12.30)$ & $H R$ & & $\begin{array}{l}\text { Age, blood pressure/ } \\
\text { hypertension, fasting } \\
\text { glucose/diabetes }\end{array}$ & ICD 8, 9: 430-438 \\
\hline
\end{tabular}

*Primary cigar smoking: current, exclusive cigar smoking with no previous history of cigarette or pipe smoking; primary cigar and/or pipe smoking: current, exclusive cigar and/or pipe smoking with no previous history of cigarette smoking; secondary cigar smoking: current, exclusive cigar smoking with previous history of cigarette or pipe smoking; secondary cigar and/or pipe smoking: current, exclusive cigar and/or pipe smoking with previous history of cigarette smoking.

was still highly elevated for oral, esophageal, and laryngeal cancer among primary cigar smokers reporting no inhalation, particularly in CPS-I which is consistent with the observation that cigar smoke is inhaled regardless of self-reported inhalation [40]. It is also notable that elevated risks of oral, esophageal, laryngeal cancers, and aortic aneurysm were observed among primary cigar smokers who smoked 1-2 cigars per day, although most of these risks did not reach statistical significance due to small sample size.

In CPS I, the risks were considerably higher for secondary cigar smokers than for primary cigar smokers for lung cancer $(\mathrm{MRs}=6.29$ and 2.1 , respectively) and COPD (MRs $=4.39$ and 1.42 , respectively). As mentioned in the Introduction, the difference in risks could be due to differences in inhalation patterns between secondary cigar smokers and primary cigar smokers. Also, irreversible damage to the lungs due to past cigarette use can also explain the higher risks of lung cancer and
COPD in secondary cigar smokers than in primary cigar smokers. These differences in risks between primary and secondary cigar smoking further reinforce the fact that exclusion of past cigarette smoking would better isolate the effects of cigar smoking for estimating disease risk.

Our results for mortality are consistent with recent studies of cigar smoking and incident cancers, such as those from the European Prospective Investigation into Cancer and Nutrition (EPIC) cohort and the International Head and Neck Cancer Epidemiology (INHANCE) Consortium. EPIC is a large multi-country cohort study of approximately half a million adults aged 35 to 70 years enrolled between 1991 and 1998 with a median of 9 years of follow up [41]. There were a total of 1,451 current (74\%) or former (26\%) cigar smokers who had never smoked cigarettes or pipes. Among the exclusive, current cigar smokers significantly elevated risks of lung $(\mathrm{HR}=3.9)$ and upper aerodigestive tract (UADT) (oral cavity, larynx, esophagus excluding esophageal adenocarcinoma) ( $\mathrm{HR}=$

Table 22 Current cigar smoking and stroke by inhalation level and cigars per day

\begin{tabular}{llllllll}
\hline Study & Cohort name & Inhalation level & Cigars per day & Effect estimate & $\mathbf{9 5 \%} \mathbf{C l}$ & Measure & Primary/secondary* \\
\hline Shanks1998 & CPS-I & 1 to 2 & 1.01 & $(0.88,1.17)$ & IRR & Primary \\
Shanks1998 & CPS-I & 3 to 4 & 1.05 & $(0.88,1.23)$ & IRR & Primary \\
Shanks1998 & CPS-I & $5+$ & 0.79 & $(0.64,0.97)$ & IRR & Primary \\
Shanks1998 & CPS-I & 1 to 2 & 0.95 & $(0.71,1.26)$ & IRR & Secondary \\
Shanks1998 & CPS-I & 3 to 4 & 0.92 & $(0.67,1.24)$ & IRR & Secondary \\
Shanks1998 & CPS-I & $5+$ & 0.89 & $(0.64,1.22)$ & IRR & Secondary \\
Shanks1998 & CPS-I & None & & 0.91 & $(0.82,1.02)$ & IRR & Primary \\
Shanks1998 & CPS-I & Slight & & 1.06 & $(0.79,1.39)$ & IRR & Primary \\
Shanks1998 & CPS-I & Moderate-deep & & 1.22 & $(0.74,1.91)$ & IRR & Primary \\
Shanks1998 & CPS-I & None & & 0.95 & $(0.76,1.18)$ & IRR & Secondary \\
Shanks1998 & CPS-I & Slight & & 0.83 & $(0.55,1.20)$ & IRR & Secondary \\
Shanks1998 & CPS-I & Moderate-deep & & 0.88 & $(0.52,1.38)$ & IRR & Secondary \\
\hline
\end{tabular}

*Primary cigar smoking: current, exclusive cigar smoking with no previous history of cigarette or pipe smoking; secondary cigar smoking: current, exclusive cigar smoking with previous history of cigarette or pipe smoking. 
Table 23 Current cigar smoking and aortic aneurysm

\begin{tabular}{|c|c|c|c|c|c|c|c|c|}
\hline Study & Cohort name & $\begin{array}{l}\text { Cigar smoker } \\
\text { deaths }\end{array}$ & $\begin{array}{l}\text { Effect } \\
\text { estimate }\end{array}$ & $95 \% \mathrm{Cl}$ & Measure & $\begin{array}{l}\text { Primary/ } \\
\text { secondary* }\end{array}$ & Adjustment & $\begin{array}{l}\text { ICD } \\
\text { codes }\end{array}$ \\
\hline \multicolumn{9}{|l|}{ Current Cigar } \\
\hline Kahn1966 & Dorn study & 24 & 2.06 & $(1.32,3.07)$ & SMR & & Age & ICD 7: 450 \\
\hline Carstensen 1987 & Swedish Census Cohort & 4 & 5.1 & $(1.33,13.19)$ & SMR & & Age, residence & ICD 8: 451 \\
\hline Shanks1998 & CPS-I & 46 & 1.76 & $(1.29,2.35)$ & IRR & Primary & Age & \\
\hline Shanks1998 & CPS-I & 31 & 2.82 & $(1.91,4.00)$ & IRR & Secondary & Age & \\
\hline \multicolumn{9}{|c|}{ Current Cigar and/or Pipe } \\
\hline Strachan 1991 & Whitehall study & & 5.4 & $(1.90,15.30)$ & OR & & Age & ICD 8: 441 \\
\hline
\end{tabular}

*Primary cigar smoking: current, exclusive cigar smoking with no previous history of cigarette or pipe smoking; primary cigar and/or pipe smoking: current, exclusive cigar and/or pipe smoking with no previous history of cigarette smoking; secondary cigar smoking: current, exclusive cigar smoking with previous history of cigarette or pipe smoking; secondary cigar and/or pipe smoking: current, exclusive cigar and/or pipe smoking with previous history of cigarette smoking.

3.5) cancers as well as any tobacco-related cancer ( $\mathrm{HR}=$ 1.6) were observed. The risk of combined lung/UADT/ bladder cancer and all tobacco-related cancer increased with increasing inhalation level and increasing duration, but significantly elevated risk of any tobacco-related cancer was still observed when no inhalation was reported. Risk of lung/UADT/bladder cancer increased with increasing cigars smoked per day and was significantly increased across all cigar sizes (small, medium, and large). In a pooled analysis of 19 studies as part of the INHANCE Consortium (comprising 13,935 cases and 18,691 controls from 1981 to 2007), the associations between tobacco smoking (cigarette, cigar and pipe) and head and neck cancers (cancers of the oral cavity, pharynx, and larynx) were assessed [42]. Roughly one-third of the study participants were from the United States (35\% of cases and 36\% of controls), and most of the remaining subjects were from Latin America (28\% of cases and $17 \%$ of controls) or Italy (18\% of cases and $29 \%$ of controls). Among never cigarette smokers, the odds ratio (OR) for ever cigar smoking and head and neck cancers was significantly elevated $(\mathrm{OR}=2.54,95 \% \mathrm{CI}=1.93,3.34)$, and increased with increasing frequency and duration of cigar smoking (p-trends $\leq 0.0001)$. At the same time, ORs for cigar and head and neck cancer were not elevated among ever cigarette smokers. In summary, the cigar associations from studies of incident disease are generally consistent with those of cause-specific mortality.

Our systematic review is subject to certain limitations. The studies included in this review were largely limited to study populations of white men in North America and Europe who smoked cigars in the 1960s or earlier. The predominant cigar type studied was the large cigar, whereas today, the US. cigar market consists of products manufactured with various shapes, sizes, tips, filters and packaging [3]. Limited data were available for a number of smoking-related cancers, including stomach, colorectal, and liver cancer. Finally, studies were often underpowered for detecting associations at the lowest levels of exposure.

Table 24 Current cigar smoking and aortic aneurysm by inhalation level and cigars per day

\begin{tabular}{|c|c|c|c|c|c|c|c|}
\hline Study & Cohort name & Inhalation level & Cigars per day & Effect estimate & $95 \% \mathrm{Cl}$ & Measure & Primary/secondary* \\
\hline Shanks1998 & CPS-I & & 1 to 2 & 1.82 & $(1.11,2.81)$ & IRR & Primary \\
\hline Shanks 1998 & CPS-I & & 3 to 4 & 0.88 & $(0.35,1.82)$ & $\mathrm{IRR}$ & Primary \\
\hline Shanks1998 & CPS-1 & & $5+$ & 2.62 & $(1.58,4.09)$ & IRR & Primary \\
\hline Shanks 1998 & CPS-I & & 1 to 2 & 3.03 & $(1.51,5.43)$ & $\mathrm{IRR}$ & Secondary \\
\hline Shanks 1998 & CPS-I & & 3 to 4 & 2.8 & $(1.34,5.16)$ & $\mathrm{IRR}$ & Secondary \\
\hline Shanks1998 & CPS-I & & $5+$ & 2.64 & $(1.26,4.85)$ & IRR & Secondary \\
\hline Shanks 1998 & CPS-1 & None & & 1.73 & $(1.22,2.39)$ & $\mathrm{IRR}$ & Primary \\
\hline Shanks1998 & CPS-I & Slight & & 1 & $(0.20,2.92)$ & $\mathrm{IRR}$ & Primary \\
\hline Shanks1998 & CPS-I & Moderate-deep & & 4.94 & $(1.59,11.52)$ & $\mathrm{IRR}$ & Primary \\
\hline Shanks1998 & CPS-I & None & & 2.18 & $(1.22,3.59)$ & IRR & Secondary \\
\hline Shanks 1998 & CPS-I & Slight & & 3.52 & $(1.69,6.47)$ & $\mathrm{IRR}$ & Secondary \\
\hline Shanks1998 & CPS-I & Moderate-deep & & 2.94 & $(0.95,6.87)$ & $\mathrm{IRR}$ & Secondary \\
\hline
\end{tabular}

*Primary cigar smoking: current, exclusive cigar smoking with no previous history of cigarette or pipe smoking; secondary cigar smoking: current, exclusive cigar smoking with previous history of cigarette or pipe smoking. 
Table 25 Current cigar smoking and chronic obstructive pulmonary disease (COPD)

\begin{tabular}{|c|c|c|c|c|c|c|c|c|c|}
\hline Study & Cohort name & Sex & $\begin{array}{l}\text { Cigar } \\
\text { smoker } \\
\text { deaths }\end{array}$ & $\begin{array}{l}\text { Effect } \\
\text { estimate }\end{array}$ & $95 \% \mathrm{Cl}$ & Measure & $\begin{array}{l}\text { Primary/ } \\
\text { secondary* }\end{array}$ & Adjustment & ICD codes \\
\hline \multicolumn{10}{|l|}{ Current Cigar } \\
\hline Kahn1966 & Dorn study & & 5 & 0.79 & $(0.25,1.86)$ & SMR & & Age & $\begin{array}{l}\text { ICD 7: 500-502, } \\
527.1\end{array}$ \\
\hline Carstensen 1987 & Swedish Census Cohort & & 1 & 1.3 & $(0.00,7.45)$ & SMR & & $\begin{array}{l}\text { Age, } \\
\text { residence }\end{array}$ & ICD 8: 490-492 \\
\hline Lange1992 & $\begin{array}{l}\text { Copenhagen } \\
\text { City Heart Study }\end{array}$ & Men & 22 & 3.7 & $\begin{array}{l}(1.10 \\
12.00)\end{array}$ & $\mathrm{HR}$ & & Age & ICD 8: 490-492 \\
\hline Lange1992 & $\begin{array}{l}\text { Copenhagen } \\
\text { City Heart Study }\end{array}$ & Women & 10 & 10 & $\begin{array}{l}(2.30 \\
48.00)\end{array}$ & $\mathrm{HR}$ & & Age & ICD 8: 490-492 \\
\hline Shanks1998 & CPS-I & & 30 & 1.42 & $(0.96,2.03)$ & $\mathrm{IRR}$ & Primary & Age & \\
\hline Shanks1998 & CPS-I & & 33 & 4.39 & $(3.02,6.16)$ & IRR & Secondary & Age & \\
\hline \multicolumn{10}{|c|}{ Current Cigar and/or Pipe } \\
\hline Wald1997 & $\begin{array}{l}\text { British United Provident } \\
\text { Association }\end{array}$ & & 40 & 1.11 & $(0.78,1.59)$ & $\mathrm{HR}$ & Primary & Age & $\begin{array}{l}\text { ICD 9: 416, 491-492, } \\
496,519\end{array}$ \\
\hline Wald1997 & $\begin{array}{l}\text { British United Provident } \\
\text { Association }\end{array}$ & & 35 & 1.68 & $(1.16,2.45)$ & $\mathrm{HR}$ & Secondary & Age & $\begin{array}{l}\text { ICD 9: } 416,491-492, \\
496,519\end{array}$ \\
\hline
\end{tabular}

*Primary cigar smoking: current, exclusive cigar smoking with no previous history of cigarette or pipe smoking; primary cigar and/or pipe smoking: current, exclusive cigar and/or pipe smoking with no previous history of cigarette smoking; secondary cigar smoking: current, exclusive cigar smoking with previous history of cigarette or pipe smoking; secondary cigar and/or pipe smoking: current, exclusive cigar and/or pipe smoking with previous history of cigarette smoking.

Given the changes in cigar use patterns in the US and elsewhere since the 1960s, this review highlights the critical need for updated estimates of mortality risks due to cigar smoking. Additional studies that include women, non-whites, and younger adults in contemporary cohorts from the 1990s or later would better reflect current trends in cigar use. Studies that distinguish primary from secondary cigar smokers and exclude other current tobacco smokers would better isolate the effects of cigar smoking from other tobacco use. Data collection and analysis that include detailed information on the types of cigars typically used, the average number of cigars smoked per day, the depth of inhalation of cigar smoke, and the number of years smoking cigars would give a better sense of any dose-response relationship. Future studies incorporating biomarkers of tobacco exposure and potential harm such as cotinine and NNAL would better assess the levels of exposure to toxic constituents

Table 26 Current cigar smoking and chronic obstructive pulmonary disease (COPD) by inhalation level and cigars per day

\begin{tabular}{llllllll}
\hline Study & Cohort name & Inhalation level & Cigars per day & Effect estimate & $\mathbf{9 5 \%}$ Cl & Measure & Primary/secondary* \\
\hline Shanks1998 & CPS-I & & 1 to 2 & 1.39 & $(0.742 .38)$ & IRR & Primary \\
Shanks1998 & CPS-I & 3 to 4 & 1.78 & $(0.893 .18)$ & IRR & Primary \\
Shanks1998 & CPS-I & $5+$ & 1.03 & $(0.372 .23)$ & IRR & Primary \\
Shanks1998 & CPS-I & 1 to 2 & 2.64 & $(1.065 .44)$ & IRR & Secondary \\
Shanks1998 & CPS-I & 3 to 4 & 4.33 & $(2.077 .97)$ & IRR & Secondary \\
Shanks1998 & CPS-I & $5+$ & 6.68 & $(3.8210 .85)$ & IRR & Secondary \\
Shanks1998 & CPS-I & None & & 1.09 & $(0.661 .70)$ & IRR & Primary \\
Shanks1998 & CPS-I & Slight & & 2.05 & $(0.664 .77)$ & IRR & Primary \\
Shanks1998 & CPS-I & Moderate-deep & & 4.52 & $(0.9113 .22)$ & IRR & Primary \\
Shanks1998 & CPS-I & None & & 3.36 & $(1.965 .39)$ & IRR & Secondary \\
Shanks1998 & CPS-I & Slight & & 7.68 & $(3.3115 .14)$ & IRR & Secondary \\
Shanks1998 & CPS-I & Moderate-deep & & 5.84 & $(2.3412 .02)$ & IRR & Secondary \\
\hline
\end{tabular}

*Primary cigar smoking: current, exclusive cigar smoking with no previous history of cigarette or pipe smoking; secondary cigar smoking: current, exclusive cigar smoking with previous history of cigarette or pipe smoking. 
Table 27 Current cigar smoking and other causes of death

\begin{tabular}{|c|c|c|c|c|c|c|c|c|c|}
\hline Study & $\begin{array}{l}\text { Cohort } \\
\text { name }\end{array}$ & $\begin{array}{l}\text { Cause } \\
\text { of death }\end{array}$ & $\begin{array}{l}\text { Cigar smoker } \\
\text { deaths }\end{array}$ & $\begin{array}{l}\text { Effect } \\
\text { estimate }\end{array}$ & $95 \% \mathrm{Cl}$ & Measure & $\begin{array}{l}\text { Primary/ } \\
\text { secondary* }\end{array}$ & Adjustment & ICD codes \\
\hline \multicolumn{10}{|l|}{ Current Cigar } \\
\hline Kahn1966 & $\begin{array}{l}\text { Dorn } \\
\text { study }\end{array}$ & Atherosclerosis & 39 & 0.97 & $(0.69,1.33)$ & SMR & & Age & ICD7: 450 \\
\hline Kahn1966 & $\begin{array}{l}\text { Dorn } \\
\text { study }\end{array}$ & Kidney cancer & 6 & 0.77 & $(0.28,1.69)$ & SMR & & Age & ICD7: 180 \\
\hline \multicolumn{10}{|c|}{ Current Cigar and/or Pipe } \\
\hline Chow1993 & $\begin{array}{l}\text { Dorn } \\
\text { study }\end{array}$ & $\begin{array}{l}\text { Nasopharyngeal } \\
\text { carcinoma }\end{array}$ & 2 & 1 & $(0.20,5.20)$ & IRR & Primary & Age and calendar year & ICD7: 146 \\
\hline Heineman 1995 & $\begin{array}{l}\text { Dorn } \\
\text { study }\end{array}$ & Colon cancer & 576 & 1.3 & $(1.10,1.40)$ & IRR & Primary & $\begin{array}{l}\text { Age, calendar time, year } \\
\text { of questionnaire response, } \\
\text { SES, sedentary job }\end{array}$ & $\begin{array}{l}\text { ICD7: 153.0- } \\
153.3\end{array}$ \\
\hline Heineman1995 & $\begin{array}{l}\text { Dorn } \\
\text { study }\end{array}$ & Rectal cancer & 169 & 1.4 & $(1.20,1.80)$ & IRR & Primary & $\begin{array}{l}\text { Age, calendar time, year } \\
\text { of questionnaire response, } \\
\text { SES, sedentary job }\end{array}$ & ICD7: 154 \\
\hline
\end{tabular}

*Primary cigar smoking: current, exclusive cigar smoking with no previous history of cigarette or pipe smoking; primary cigar and/or pipe smoking: current, exclusive cigar and/or pipe smoking with no previous history of cigarette smoking; secondary cigar smoking: current, exclusive cigar smoking with previous history of cigarette or pipe smoking; secondary cigar and/or pipe smoking: current, exclusive cigar and/or pipe smoking with previous history of cigarette smoking.

and intermediate health effects in cigar smokers, especially across cigar types and in comparison with cigarette smokers.

\section{Conclusions}

In summary, cigar smoking carries many of the same health risks as cigarette smoking, which is consistent with the fact that the two products share similar levels of many of the same harmful constituents. Mortality risks from cigar smoking vary by level of exposure as measured by cigars per day and inhalation level. We have observed that some risks associated with cigar smoking can be as high or higher than those associated with cigarette smoking, especially at the highest doses and levels of inhalation for cigar smoking. However, even when no inhalation of cigar smoke is reported, risks of death from cancers of the upper aerodigestive tract (oral cavity, larynx, esophagus) are still highly elevated. This body of research would be strengthened by future studies that focus on primary cigar smoking, incorporate more contemporary and diverse study populations to better reflect the current patterns of cigar use in the US. Ideally, these studies would also collect detailed information on cigar type, level of exposure, and biomarkers of exposure and potential harm.

\section{Additional file}

Additional file 1: Supplemental Web References.

\section{Competing interests}

The authors declare that they have no competing interests.
Authors' contributions

CMC performed the literature search, selected the papers of interest, extracted the data, and wrote the manuscript. CGC performed the literature search, selected the papers of interest, and extracted the data for this review. BLR gave important contributions for interpretation of data and writing of the manuscript. BJA conceived and coordinated the study. All authors read and approved the final manuscript.

\section{Acknowledgements}

We thank Nancy Chang, MD for reviewing the ICD groupings of smoking-related diseases.

\section{Disclaimer}

The information in this article is not a formal dissemination of information by the FDA and does not represent agency position or policy. The contents are the responsibility of the authors alone.

Received: 4 August 2014 Revised: 5 August 2014 Accepted: 5 March 2015 Published online: 24 April 2015

\section{References}

1. Deeming Tobacco Products To Be Subject to the Federal Food, Drug, and Cosmetic Act, as Amended by the Family Smoking Prevention and Tobacco Control Act; Regulations on the Sale and Distribution of Tobacco Products and Required Warning Statements for Tobacco Products [http://www. regulations.gov/\#!documentDetail;D=FDA-2014-N-0189-0001]

2. Centers for Disease Control and Prevention (CDC); Consumption of cigarettes and combustible tobacco-United States, 2000-2011. MMWR Morb Mortal Wkly Rep 2012, 61:565-569.

3. Delnevo CD, Giovenco DP, Ambrose BK, Corey CG, Conway KP: Preference for flavoured cigar brands among youth, young adults and adults in the USA. Tob Control 2014; Apr 10. doi: 10.1136/tobaccocontrol-2013-051408. [Epub ahead of print]

4. Cullen J, Mowery P, Delnevo C, Allen JA, Sokol N, Byron MJ, et al. Seven-year patterns in US cigar use epidemiology among young adults aged 18-25 years: a focus on race/ethnicity and brand. Am J Public Health. 2011;101:1955-62.

5. Centers for Disease Control and Prevention (CDC); Tobacco product use among middle and high school students-United States, 2011 and 2012. MMWR Morb Mortal Wkly Rep 2013, 62:893-897.

6. Hoffmann D, Hoffmann I. Chemistry and Toxicology. National Cancer Institute, Smoking and Tobacco Control, Monograph 9: Cigars Health Effects and Trends 1998,55-104 http://cancercontrol.cancer.gov/brp/tcrb/ monographs/. 
7. IARC Working Group on the Evaluation of Carcinogenic Risks to Humans; Tobacco smoke and involuntary smoking. IARC Monogr Eval Carcinog Risks Hum 2004, 83:1-1438.

8. Sasco AJ, Secretan MB, Straif K. Tobacco smoking and cancer: a brief review of recent epidemiological evidence. Lung Cancer. 2004;45 Suppl 2:S3-9.

9. Nonnemaker J, Rostron B, Hall P, MacMonegle A, Apelberg B. Mortality and Economic Costs from Regular Cigar Use in the United States, 2010. Am J Public Health 2014, (in press).

10. IOM (Institute of Medicine). Finding What Works in Health Care: Standards for Systematic Reviews. Washington, DC: The National Academies Press; 2011.

11. Stroup DF, Berlin JA, Morton SC, Olkin I, Williamson GD, Rennie D, et al. Meta-analysis of observational studies in epidemiology. JAMA. 2000;283:2008-12

12. Higgins JPT, Green S (editors). Cochrane Handbook for Systematic Reviews of Interventions Version 5.1.0 [updated March 2011]. The Cochrane Collaboration, 2011. Available from www.cochrane-handbook.org

13. The Health Consequences of Smoking. Report of the Surgeon General. Atlanta, GA: Dept. of Health and Human Services, Centers for Disease Control and Prevention, National Center for Chronic Disease Prevention and Health Promotion, Office on Smoking and Health; 2004.

14. IARC Working Group on the Evaluation of Carcinogenic Risks to Humans Personal habits and indoor combustions. Volume $100 \mathrm{E}$. A review of human carcinogens. IARC Monogr Eval Carcinog Risks Hum 2012, 100:1-538.

15. Best EWR, McGregor JT. A Canadian study of smoking and health. Ottawa: Department of National Health and Welfare; 1966.

16. Ben-Shlomo Y, Smith GD, Shipley MJ, Marmot MG. What determines mortality risk in male former cigarette smokers? Am J Public Health. 1994;84:1235-42

17. Carstensen JM, Pershagen G, Eklund G. Mortality in relation to cigarette and pipe smoking: 16 years' observation of 25,000 Swedish men. J Epidemiol Community Health. 1987;41:166-72.

18. Chao A, Thun MJ, Henley SJ, Jacobs EJ, McCullough ML, Calle EE. Cigarette smoking, use of other tobacco products and stomach cancer mortality in US adults: The Cancer Prevention Study II. Int J Cancer. 2002;101:380-9.

19. Cole TJ, Gilson JC, Olsen HC. Bronchitis, smoking and obesity in an english and a Danish town: male deaths after a 10 year follow up. BULL PHYSIO-PATH RESP. 1974;10:657-79.

20. Chow W, McLaughlin JK, Hrubec Z, Nam J, Blot WJ. Tobacco use and nasopharyngeal carcinoma in a cohort of US veterans. Int J Cancer. 1993;55:538-40.

21. Chow W, Schuman LM, McLaughlin JK, Bjelke E, Gridley G, Wacholder S, et al. A cohort study of tobacco use, diet, occupation, and lung cancer mortality. Cancer Causes Control. 1992;3:247-54.

22. Doll $R$, Peto R. Mortality in relation to smoking: 20 years' observations on male British doctors. Br Med J. 1976;2:1525-36.

23. Haheim LL, Holme I, Hjermann I, Leren P. Smoking habits and risk of fatal stroke: 18 years follow up of the Oslo Study. J Epidemiol Community Health. 1996:50:621-4.

24. Heineman EF, Zahm SH, McLaughlin JK, Vaught JB. Increased risk of colorectal cancer among smokers: Results of a 26-year follow-up of US veterans and a review. Int J Cancer. 1994;59:728-38.

25. Hsing AW, McLaughlin JK, Hrubec Z, Blot WJ, Fraumeni J. Cigarette smoking and liver cancer among US veterans. Cancer Causes Control. 1990;1:217-21.

26. Jacobs EJ, Thun MJ, Apicella LF. Cigar smoking and death from coronary heart disease in a prospective study of US men. Arch Intern Med. 1999;159:2413-8.

27. Jajich $\mathrm{CL}$, Ostfeld $\mathrm{AM}$, Freeman $\mathrm{DH}$. Smoking and coronary heart disease mortality in the elderly. JAMA. 1984;252:2831-4.

28. Kahn HA. The Dorn study of smoking and mortality among U.S. veterans: report on eight and one-half years of observation. Natl Cancer Inst Monogr. 1966 Jan;19:1-125.

29. Sandler DP, Comstock GW, Helsing KJ, Shore DL. Deaths from all causes in non-smokers who lived with smokers. Am J Public Health. 1989;79:163-7.

30. Lange P, Nyboe J, Appleyard M, Jensen G, Schnohr P. Relationship of the type of tobacco and inhalation pattern to pulmonary and total mortality. Eur Respir J. 1992:5:1111-7.

31. Shanks TG, Burns DM. Disease consequences of cigar smoking. National Cancer Institute, Smoking and Tobacco Control, Monograph 9: Cigars Health Effects and Trends 1998,105-160. http://cancercontrol.cancer.gov/ brp/tcrb/monographs/

32. Shaper AG, Wannamethee SG, Walker M. Pipe and cigar smoking and major cardiovascular events, cancer incidence and all-cause mortality in middle-aged British men. Int J Epidemiol. 2003;32:802-8.
33. Shapiro JA, Jacobs EJ, Thun MJ. Cigar smoking in men and risk of death from tobacco-related cancers. J Natl Cancer Inst. 2000;92:333-7.

34. Strachan DP. Predictors of death from aortic aneurysm among middle-aged men: the Whitehall study. Br J Surg. 1991;78:401-4.

35. Wald NJ, Watt HC. Effect on mortality of switching from cigarettes to pipes or cigars - American study supported conclusions - Authors' reply. BMJ. 1998;316:863-4.

36. Gordon T, Kannel WB, McGee D. Death and coronary attacks in men after giving up cigarette smoking: a report from the Framingham study. Lancet. 1974;2:1345-8.

37. Henley SJ, Thun MJ, Connell C, Calle EE. Two large prospective studies of mortality among men who use snuff or chewing tobacco (United States). Cancer Causes Control. 2005;16:347-58.

38. Breslow NE, Day NE. Statistical methods in cancer research. Volume II-The design and analysis of cohort studies. IARC Sci Publ. 1987;(82):1-406.

39. Rothman KJ, Greenland S. Modern Epidemiology. Philadelphia: Lipponcott Williams \& Wilkins; 1998

40. McDonald LJ, Bhatia RS, Hollett PD. Deposition of cigar smoke particles in the lung: evaluation with ventilation scan using (99 m) Tc-labeled sulfur colloid particles. J Nucl Med. 2002;43:1591-5.

41. McCormack VA, Agudo A, Dahm CC, Overvad K, Olsen A, Tjonneland A, et al. Cigar and pipe smoking and cancer risk in the European prospective investigation into cancer and nutrition (EPIC). Int J Cancer. 2010;127:2402-11.

42. Wyss A, Hashibe M, Chuang SC, Lee YCA, Zhang ZF, Yu GP, et al. Cigarette cigar, and pipe smoking and the risk of head and neck cancers: pooled analysis in the international head and neck cancer epidemiology consortium 1122. Am J Epidemiol. 2013;178:679-90.

43. Correction. Mortality in relation to smoking. Br Med J. 1977;1:388.

\section{Submit your next manuscript to BioMed Central and take full advantage of:}

- Convenient online submission

- Thorough peer review

- No space constraints or color figure charges

- Immediate publication on acceptance

- Inclusion in PubMed, CAS, Scopus and Google Scholar

- Research which is freely available for redistribution

Submit your manuscript at www.biomedcentral.com/submit 